\title{
An updated phylogeny of Anisoptera including formal convergence analysis of morphological characters
}

\author{
ALEXANDER BLANKE ${ }^{1}$, CAROLA GREVE ${ }^{1}$, RAJMUND MOK S ${ }^{2}$, \\ FELIX BECKMANN ${ }^{3}$ and BERNHARD MISOF${ }^{1}$ \\ ${ }^{1}$ Zoologisches Forschungsmuseum Alexander Koenig, Zentrum für Molekulare Biodiversität, Adenauerallee 160, Bonn, \\ 53113,Germany, ${ }^{2}$ Swiss Light Source, Paul Scherrer Institut, Villigen, 5232, Switzerland and ${ }^{3}$ Institute of Materials Research, \\ Helmholtz-Zentrum Geesthacht, Max-Planck-Street 1, Geesthacht, 21502, Germany
}

\begin{abstract}
Deep level relationships among Anisoptera (dragonflies) are unresolved. Molecular markers applied thus far have not been particularly useful for resolving relationships at the family level. Previous morphological studies have depended heavily on characters of wing venation and articulation which are believed to display considerable degrees of homoplasy due to adaptations for different flight modes. Here, we present a comprehensive anatomical dataset of the head morphology of Anisoptera focusing on muscle organization and endoskeletal features covering nearly all families. The characters are illustrated in detail and incorporated into an updated morphological character matrix covering all parts of the dragonfly body. Phylogenetic analysis recovers all families as monophyletic clades except Corduliidae, Gomphidae as sister group to all remaining Anisoptera, and Austropetaliidae as sister group to Aeshnidae (=Aeshnoidea). The position of Petaluridae and Aeshnoidea to each other could not be resolved. Libelluloidea is monophyletic with Neopetalia and Cordulegastridae as first splits. Chlorogomphidae is sister to an assemblage of monophyletic [Synthemistidae + ('Corduliidae' + Libellulidae)]. In addition, we applied a recently published formal approach to detect concerted convergence in morphological data matrices to uncover possible homoplasies. Analyses show that especially head and thorax characters may harbour homoplasies. After exclusion of possible homoplastic characters, Gomphidae is corroborated as sister group to all remaining Anisopterà.
\end{abstract}

\section{Introduction}

Vein branching patterns and wing base sclerite configuration have been routinely used in insect phylogenetics and proved an invaluable tool to compare fossils with the recent insect fauna (Trueman, 1996). However, it has been proposed that wing characters display a considerable degree of convergence (Fleck et al., 2008a). This is especially true for Odonata (Bybee etal., 2008; Carle etal., 2008; Fleck etal., 2008a). Several authors have shown that the effects of wing size reduction and different flight styles may be responsible for parts of the

Correspondence: Alexander Blanke, Zoologisches Forschungsmuseum Alexander Koenig, Zentrum für Molekulare Biodiversität, Adenauerallee 160, 53113 Bonn, Germany. E-mail: blanke@uni-bonn.de Unpublished for the purposes of zoological nomenclature (Art. 8.2, ICZN)

(c) 2013 The Royal Entomological Society wing vein characteristics in Odonata, thus potentially biasing phylogenetic signal. For example, functional dependence between the costal region (the leading edge of the wing) is believed to have an influence on the configuration of more posteriorly located wing parts (Wootton, 1992).

The effect of convergent evolution of groups of characters is called concerted convergence (Patterson \& Givnish, 2002). It is assumed that similar selective pressures result in convergent evolution of character groups which may inflate node support values in tree reconstructions. Recently, Holland et al. (2010) proposed an approach to detect these character groups in morphological data matrices by applying permutation tests of character compatibility.

In this study we pursue two main goals. First, we aim to compile a comprehensive morphological character matrix to infer a robust deep-level phylogeny of dragonflies by extending 
the currently largest morphological data matrix covering all parts of the dragonfly body (Rehn, 2003; Bybee et al., 2008). Our focus for the addition of new characters is the head region. The head as a character system is underrepresented in dragonfly phylogenetics (only 13 of 153 characters, i.e. 8.5\%; Bybee et al., 2008), but has proven useful to infer relationships amongst various other groups of insects (Wipfler etal., 2011, 2012; Blanke etal., 2012a,2012c).

Secondly, we investigate the degree of concerted convergence in this extended data matrix in order to explore potential confounding signal within morphological characters with Holland's etal. (2010) approach. Subsequently, we analyse which functional groups of characters are prone to concerted convergence.

\section{Background}

Odonata are classified into two major groups: Zygoptera (damselflies) and Epiprocta (fide Lohmann (1996)) comprising the sister groups Anisoptera (dragonflies) and Anisozygoptera, containing one family, Epiophlebiidae, with three relict species (Li etal., 2012).

The monophyly of the families within Anisoptera is generally accepted except for the morphologically very heterogeneous Corduliidae. However, the relationships between these families are not congruently resolved. In molecular studies especially the positions of Gomphidae (clubtails), Aeshnidae + Austropetaliidae (=Aeshnoidea), Petaluridae (petaltails) and Cordulegastridae (spiketails) are incongruently resolved depending on the molecular markers chosen for analysis (Fig. 1). For example, Misof etal. (2001) recovered a clade Gomphidae + Petaluridae which is sister to the remaining Anisoptera. In this study, Aeshnoidea were recovered as the sister group to Libelluloidea (Chlorogomphidae + Neopetaliidae + Cordulegastridae + Macromiidae +

Corduliidae + Libellulidae). Carle etal. (2008) based on nuclear and mitochondrial rRNAs, and EF1- $\alpha$ markers proposed Aeshnoidea as sister to all remaining Anisoptera and Gomphidae as sister group to Petaluridae + Libelluloidea. Taking secondary structure information of mtRNA gene sequences into account, Fleck etal. (2008b) suggested monophyletic Aeshnomorpha (Gomphidae + Petaluridae + Aeshnoidea) as sister group to Libelluloidea. Letsch etal. (2009) analysed mitochondrial as well as nuclear sequence data and refined the secondary structure analysis approach by identifying local structure constraints of each sequence, thereby uncovering phylogenetic signal in folded RNA structures. Basically, this analysis pointed towards the results of Carle etal. (2008), although the position of Gomphidae and Petaluridae did not receive strong support.

Morphological analyses of the interfamily relationships within Anisoptera are equally plagued by incongruent results. Based on wing characters Trueman (1996) proposed Petaluridae as sister group to the remaining Anisoptera and Aeshnidae + Chlorogomphidae as sister to Gomphidae + the remaining Libelluloidea. Carle (1982), using a less exclusive (a)

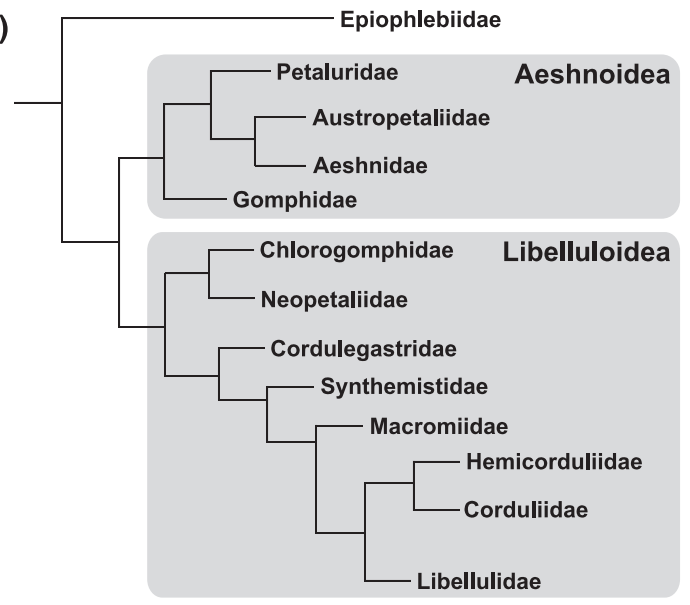

1

2

3

4

5

6

7

8

9

10

\section{(b)}

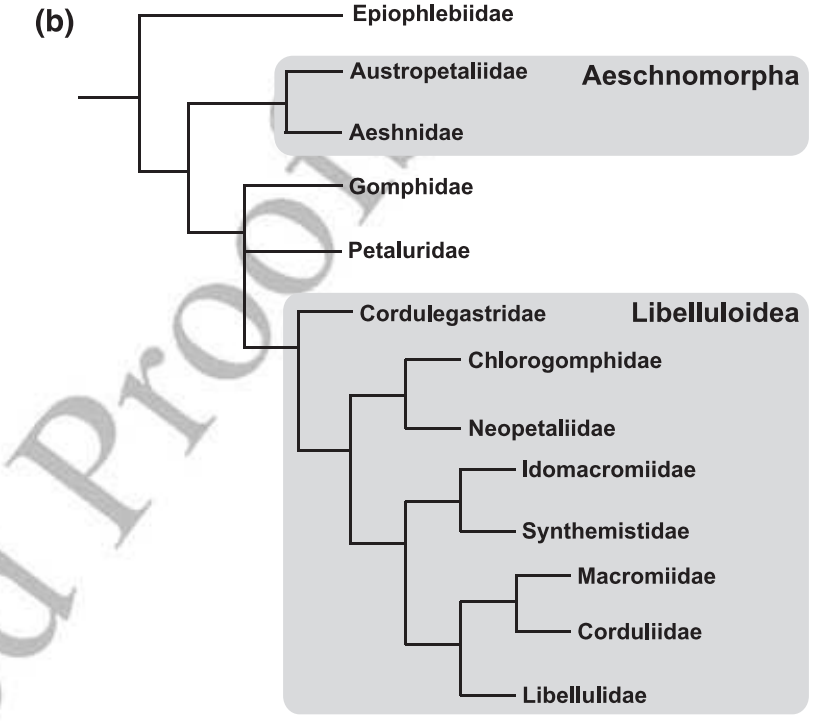

Fig. 1. The two principal hypotheses concerning the deep relationships inside Anisoptera. (a) Tree reconstruction of Fleck et al. (2008b) based on mtRNA sequences and RNA secondary structure information. (b) Tree reconstruction of Letsch etal. (2009) using mtRNA and rRNA sequences and improved RNA secondary structure models.

set of characters including thorax and abdominal characters, proposed Gomphidae as sister group to the remaining Anisoptera, whereas Chlorogomphidae and Cordulegastridae were placed as basal Libelluloidea. In contrast Pfau (1991) placed Aeshnidae as sister to the remaining Anisoptera based on functional morphological analyses of genitalia. Using a groundplan approach, Bechly (1995) placed Petaluridae as sister to extant Anisoptera and Gomphidae as sister to Libelluloidea. Rehn (2003) proposed Petaluridae as sister to all remaining Anisoptera and Gomphidae as sister to Aeshnidae + Libelluloidea using characters from the whole dragonfly body. Rehns' (2003) analysis put a strong focus on the relationships of Zygoptera, thereby ignoring some anisopteran families (e.g. Austropetaliidae, Neopetaliidae, and Chlorogomphidae). Bybee etal. (2008) used the matrix of 
Rehn (2003) in his combined molecular and morphological analysis and extended it by several characters and many taxa to cover outgroup taxa and to increase resolution within Anisoptera.

All morphological data matrices used in formal cladistic analyses of odonatan relationships are largely dependent on characters of wing venation and articulation (Trueman, 1996; von Ellenrieder, 2002; Rehn, 2003; Ballare \& Ware, 2011) which have also been used in a combined molecular and morphological approach (Bybee etal., 2008). The last comprehensive account on odonate phylogeny derived 81 out of 153 characters (53\%) from wing venation or wing articulation (Rehn, 2003).

Additionally, the majority of other characters are derived from the copulatory system. Dragonflies exhibit a unique mode of sperm transfer via a secondary copulatory system located at the second and third abdominal segments of males. Spermatophores are transferred to this apparatus by males prior to copulation. Females are then grasped at the neck by males with the claspers of the abdominal tip (copulatory tandem) and collect sperm from the male secondary copulatory system. Due to the absence of the secondary copulatory apparatus outside Odonata, polarization of characters associated with this character system is impossible. The situation is different for the female ovipositor: monophyly of Zygoptera and Anisoptera could be corroborated, the position of Epiophlebiidae and the phylogenetic relationships between anisopteran families, however, remain unclear (Klass, 2008; Matushkina, 2008a,2008b).

\section{Materials and methods}

We collected data of the outer and inner head anatomy for all currently recognized families except Gomphomacromiidae and Synthemistidae resulting in 31 datasets (see Table S1) Additional data for adults and nymphs were gathered from the literature. For brevity terminals are mentioned only with their generic name in the following.

\section{SEM and visual observations}

The outer morphology was assessed with SEM and observation with a Zeiss Stemi 2000C binocular (Carl Zeiss AG, Oberkochen, Germany). For SEM specimens were transferred in a series of steps into $100 \%$ ethanol, critical point dried (Model E4850, BioRad, Hercules, CA, USA), and sputter coated (Model Hummer VII, Anatech, Union City, CA). SEM was performed on a Hitachi S-2460N (Hitachi Ltd., Chiyoda, Tokyo, Japan) using a new type of rotatable sample holder (Pohl, 2010).

\section{Computer tomography}

The anatomy of specimens was investigated using synchrotron micro-Computer Tomography (SR-microCT) (Betz etal., 2007). Prior to scanning, samples were critical point dried (CPD) (Model E4850, BioRad, Hercules, CA, USA) and mounted on specimen holders. Generally, X-ray imaging has a high penetrating power and allows visualization of large specimens without the need for sectioning. SR-microCT offers a true 3D spatial resolution of up to $1 \mu \mathrm{m}$ with moderate resolving power of tissues and tissue interfaces.

Specimens were scanned either at the German electron synchrotron accelerator (DESY, Hamburg, Germany; Beckmann etal., 2008), at the Swiss Light Source electron synchrotron accelerator (SLS, Villigen, Switzerland; Stampanoni etal., 2010) or at the high-resolution computed tomography scanner v-tome-x s (GE phoenix-x-ray, Steinmann-Institut, Bonn, Germany) (Table S1). The DESY and SLS X-ray sources were optimized for high-density and spatial resolution (1-10 um) imaging with monochromatic X-rays. A single 3D volume of typically $3.7 \mathrm{~mm}^{3}$ can be acquired in about $12 \mathrm{~min}$ at SLS.

The tomography station BW2 (DESY) operated by Helmholtz-Zentrum Geesthacht (HZG, Geesthacht, Germany) is optimized for performing high-density resolution microtomography (Beckmann etal., 2008). All facilities provide floating point data as well as 16-bit TIFF image files and volume data files (.vgi-format) ready for analysis in the free and the proprietary Volume Graphics software packages (Volume Graphics, Heidelberg, Germany).

Datasize for each specimen ranges between 1500 and 3000 images (or 3-12 GB of raw data) depending on specimen size, magnification and quality of the back projections. The raw data are available upon request from the corresponding author and will be deposited in MorphDbase (https://www.morphdbase.de/).

The provided volume data (.vgi-files) were analysed with the free myVGL v2.0 64bit viewer (Volume Graphics, Heidelberg, Germany). Segmentation and rendering of single structures was accomplished using Reconstruct (Fiala, 2005) and Blender (http://www.blender.org). Both software packages are distributed under the General Public License (GPL) licence. Final tables and figures were edited with GIMP, Inkscape and Scribus (all GPL). A table showing the homologized cephalic musculature of the investigated odonates can be found in Table S2.

\section{Testing for concerted convergence}

For concerted convergence analysis (CCA) we applied the formal approach proposed by Holland etal. (2010) which aims to identify groups of characters upon which convergent evolution probably acted (concerted convergent characters). The proposed workflow (Fig. 2) has been successfully used to detect concerted convergence among morphological characters coding deep pterygote splits (Blanke etal., 2012b). The workflow is only roughly explained in the following; details on the general procedure can be found in Holland et al. (2010) and on the modifications used in the present study in Blanke etal. (2012b). 


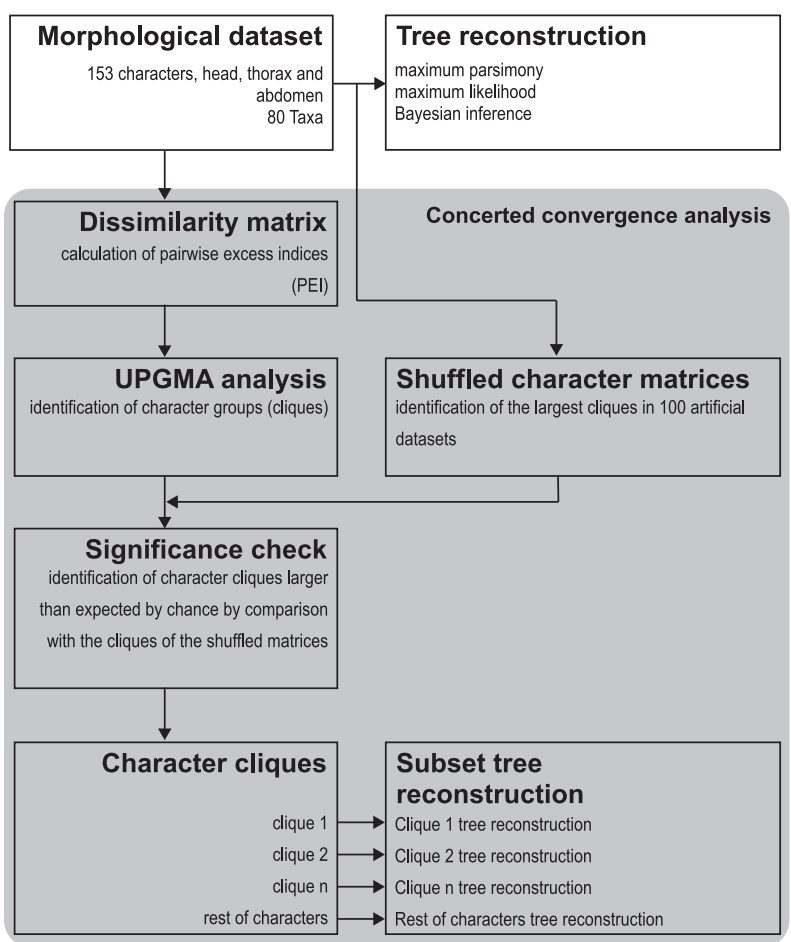

Fig. 2. Principal workflow of the data analysis after character compilation derived from the study of Holland etal. (2010). Note that tree reconstruction of the complete data and convergence analysis are performed independently of each other.

In principle, the method performs permutation tests of pairwise character compatibility of a morphological character matrix (see File S1 and Table S3) using the pairwise excess index (PEI) as a measure of fit of two randomly chosen characters on a tree constructed from just these two characters (see Table S4). Pairwise compatible characters can be grouped into clusters depending on their PEI using a standard clustering method (UPGMA; see File S2). The significance of the cluster size is assessed using a cutoff value derived from testing (PEI and UPGMA) of 1000 shuffled character matrices with equal size and parsimony index (for details see Holland etal., 2010). All cliques of the empirical dataset, which are larger than the smallest clique size generated with the shuffled artificial character matrices, are significant. These character clusters, which are larger than expected by chance alone, can then be used for tree inference. The plausibility of hypotheses supported by trees reconstructed from the clique characters as well as the remaining character set can be used to interpret the pairwise compatibility of characters. An analysis of the type of characters and their distribution among cliques may uncover groups of characters with a high probability of interdependence. The whole test needs no initial tree and is therefore independent of morphological and molecular tree inferences. However, it is possible to identify potentially problematic morphological characters by calculating the homoplasy excess for each character on a random subset of 1000 molecular trees (Holland et al., 2010).
We did not follow this approach here, because the characters relevant for the phylogenetic placement of Gomphidae and Aeshnoidea have low excess values. Therefore, exactly the characters relevant for the main questions of this paper would have been excluded by testing against the molecular tree inference (see File S3 for a detailed molecular tree and File S8 for the excess distribution of the morphological characters on the molecular trees).

In an UPGMA analysis (using PAUP v4.0b10) we calculated a tree of the pairwise excess matrix received from PEI calculation of the complete dataset (see File S2) to identify character cliques. The significance value for the largest randomly generated clique was size 23 , therefore indicating one significant character clique in the complete empirical dataset. The character clique as well as the remaining character set were used for tree reconstruction using maximum parsimony. Reconstructed strict consensus trees of these character subsets were compared with the initial strict consensus tree of the complete dataset.

We also classified all characters into seven groups: head, thorax, wing, abdomen, genitalia, anatomic characters and nymphal characters and recorded which characters grouped together in cliques and whether whole groups clustered together in cliques.

\section{Molecular data}

For the initial excess distribution test we compiled a molecular dataset with corresponding taxon selection to our morphological data matrix in which we used $12 \mathrm{~S}, 16 \mathrm{~S}, 18 \mathrm{~S}$ and $28 S$ rRNA sequences and sequences of the proteincoding genes Histone $\mathrm{H} 3$ and cytochrome c oxidase subunit II (COII) (Table S1). All sequences were downloaded from NCBI Genbank. Taxa were only included if represented by at least three genes (considering each mitochondrial gene as independent). We only considered $12 S$ sequences with at least 313 base pairs (bp), $16 \mathrm{~S}$ sequences with at least $393 \mathrm{bp}, 18 \mathrm{~S}$ with at least $560 \mathrm{bp}, 28 \mathrm{~S}$ with at least $1019 \mathrm{bp}$, COII with at least $458 \mathrm{bp}$ and complete or nearly complete sequences of Histone H3. If molecular data of taxa were not publicly available or did not pass our selection criteria, we chose sequences of other species, preferably within the same genus, or within the same family (see Table S1).

\section{Alignment procedure}

All genes were aligned separately with MAFFT (Katoh etal., 2002) choosing the L-INS-i algorithm for $12 \mathrm{~S}, 16 \mathrm{~S}$, $18 S$ rRNA sequences and COII, the E-INS-i algorithm for $28 S$ rRNA sequences and the G-INS-i algorithm for Histone H3 (Katoh etal., 2005). Subsequent masking of the alignments was carried out with Aliscore v0.2 (Misof \& Misof, 2009), which identifies putative ambiguously aligned regions in multiple sequence alignments using a sliding window approach. For gap treatment (g), window size (ws) and random pairwise comparisons (pc), the following settings were 
used: $\mathrm{g}=$ ambiguous characters, ws $=$ six positions, $\mathrm{pc}=4$ $x$ number of taxa. Ambiguous positions were masked and the masked alignments were concatenated using FASconCAT v1.0 (Kück, 2010 \#2714). Finally, the complete molecular dataset comprised 5773 characters, of which the $16 \mathrm{~S}$ partition accounted for 466 , the $18 S$ partition for 1821 , the $28 S$ partition for 2152 , the $12 S$ partition for 361, the COII partition for 647 and the Histone $\mathrm{H} 3$ partition for 326 sites.

\section{Tree calculations}

The morphological data were analysed using maximum parsimony and Bayesian inference. Parsimony analyses and Bremer/bootstrap support calculations of the morphological data were carried out with TNT (Goloboff etal., 2008) using 1000 heuristic searches starting with random addition of taxa (TBR branch swapping; all characters treated as unordered). Bayesian inference of the morphological data was conducted using MrBayes v3.2 (Huelsenbeck \& Ronquist, 2001; Ronquist \& Huelsenbeck, 2003). The MK model was applied, with among-character rate variation modelled with gamma distributed rates across characters with four discrete rate categories. Priors were set adopting the default settings of MrBayes v3.2. Two parallel analyses were run with random starting trees and four Metropolis coupled Markov chains (MCMC) for 10000000 generations with the temperature set to 0.3 . Every 100th generation was sampled to yield a posterior probability distribution of 100000 trees. After discarding the first 25000 trees of each run as burn-in trees, a 50\% majority rule consensus tree was calculated from the sampled trees of both runs. Support values are given in parentheses with the following order: (Bremer support (BR)/parsimony bootstrap $(\mathrm{PB}) /$ Bayes posterior probability (PP)).

We used constrained tree reconstruction (CTR) executing the 'move branch mode' in Winclada v1.00.08 (Nixon, 2002) to explore the character state implications of alternative hypotheses encountered in the literature. These alternative hypotheses were: Epiophlebia as sister to Cordulegastridae (EC hypothesis; Dumont etal. (2010)); Aeshnomorpha as sister to all other Anisoptera (AA hypothesis; Letsch etal. (2009)); and Aeshnoidea as sister group to Libelluloidea (AL hypothesis; Fleck etal. (2008b)).

The ML analysis of the molecular data (File S3) was conducted using the GTR $+\Gamma+\mathrm{I}$ model. To optimize model parameter estimation for each gene, the dataset was partitioned into (1) $16 \mathrm{~S}$, (2) $18 \mathrm{~S}$, (3) $28 \mathrm{~S}$, (4) $12 \mathrm{~S}$, (5) COII and (6) Histone H3. Node support for the best-scoring ML tree was evaluated with 1000 rapid bootstrap replicates (Stamatakis etal., 2008).

\section{Results}

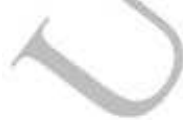

\section{Morphological data matrix}

The morphological data matrix is based on that of Rehn (2003) and the proposed extensions of Bybee etal. (2008). A character discussion can be found in Rehn (2003); a complete character list is included in File S1. Several characters of the matrices of Rehn (2003) and Bybee etal. (2008) were not included in the phylogenetic analyses, since they are specific for fossil taxa or zygopteran relationships. Characters for which homology hypotheses are unclear were also not included in the analyses. Please refer to Table S2 for a complete commented list. We recoded several characters according to the suggestions of Lee \& Bryant (1999) by splitting up character parts (coded as absent or present) and character variables (e.g. colours schemes).

The present matrix is composed of 13 head characters, 5 thorax characters, 47 characters related to wing articulation and venation, 4 abdominal characters, 13 male copulatory characters, 18 nymphal characters and 20 characters related to the inner anatomy (mainly derived from the head).

\section{Proposed phylogenetic characters}

Characters 0-11 are derived from Rehn (2003).

12. Shape of vertex and location of ocelli: (0) transverse protuberance with lateral ocelli located at the lateral border and middle ocellus anteriorly; (i) small protuberance with all ocelli located on the vertex covering it almost completely; (ii) large transverse oriented plate with middle ocellus located anteriorly and lateral ocelli located at the posterior side at the base; (iii) flat with all ocelli located on the vertex; (iv) two protuberances or horn like structures with lateral ocelli located at distal sides and middle ocellus anteriorly; (v) conical with all ocelli located on the vertex. This character is a modification of character 13 of the Rehn (2003) matrix taking into account the relative position of the ocelli and refining the structure definitions of the vertex. The vertex is a large transverse oriented plate with a distinct ocellus organization in Epiophlebia, whereas it is a transverse protuberance in all studied Aeshnidae, Cordulegastridae, Libellulidae, Synthemistidae and most Corduliidae. The vertex forms a small protuberance with all ocelli located on the vertex in Austropetaliidae. In Gomphidae, Macromiidae, Tachopteryx and Procordulia it forms two protuberances or horn-like structures. All Petaluridae except Tachopteryx show a conical vertex with all ocelli located on the vertex.

Characters 13-55 and 57 and 58 are derived from Rehn (2003).

Character 56 is derived from (Bybee etal., 2008).

59. Wings with several reddish spots in the C-Sc-Ra area: (0) absent; (1) present. Several distinct reddish spots in the C$\mathrm{Sc}-\mathrm{Ra}$ area of the wings are present in the Neopetaliidae and Austropetaliidae studied.

Characters $60,64-66 ; 68 ; 70 ; 71$ and $73-76$ are derived from Rehn (2003). 
Characters 61; 62 and 77 are derived from (Bybee etal., 2008).

63. Male mesotibial spines: (0) not quadrangular; (1) quadrangular (Garrison etal., 2006). The male mesotibial spines are quadrangular in all studied Cordulegastridae.

67. Anterior hamuli directed medially: (0) no; (1) yes (Carle \& Louton, 1994). The anterior hamuli are directed medially in all Aeshnoidea studied.

69. Anterior lamina with elongate medial cleft: (0) absent; (1) present (Carle \& Louton, 1994). An elongate medial cleft is present in all Aeshnoidea studied. It is absent in all other odonates.

72. Posterior hamules: (0) present; (1) vestigial (Carle \& Louton, 1994). The posterior hamules are vestigial in all Aeshnoidea studied.

Characters 78 and 79 are derived from Rehn (2003).

80. Abdominal terga 5-8 with ventroapical tufts of long black hairs: (0) absent; (1) present (Carle \& Louton, 1994). Ventroapical tufts of long black hairs on the abdominal terga 5-8 are present in Neopetalia and absent in all other odonates studied.

Character 81 is derived from (Bybee etal., 2008).

82. Nymph with pyramidal to spike-like horn between the eyes: (0) absent; (1) present (Needham \& Westfall, 1955). A conspicuous spike-like horn between the eyes is present in the Macromiidae investigated.

Characters 83-88 are derived from Rehn (2003).

Character 89 is derived from (Bybee etal., 2008).

90. First flagellum of nymphal antenna: (0) thinner than pedicellus; (1) thicker or at least as thick as pedicellus (Needham \& Westfall, 1955). All studied Gomphidae and Petaluridae possess a first flagellum which is at least as thick or thicker as the pedicellus.

91. Fourth antennal segment very short or vestigial in nymph: (0) absent; (1) present (Needham \& Westfall, 1955). The fourth antennal segment is very short in all studied Gomphidae.

Characters 92 and 93 are derived from (Bybee et al., 2008).

94. Spur of moveable hook: (0) robust; (1) thin and setae-like (Fleck, 2011). The spur of the moveable hook is thin and setae-like in all Cordulegastridae studied and Neopetalia, whereas it is robust in all Petaluridae (Fleck, 2011).

Character 95 is derived from (Bybee etal., 2008).

96. Hind legs of nymph: (0) at least twice as long as abdomen; (1) longer than abdomen, but less than twice as long; (2) at most as long as abdomen (Needham
\& Westfall, 1955). The nymphal hind legs are more than twice as long as the abdomen in all studied Macromiidae and Zygonyx. The hind legs are shorter or as long as the abdomen in Epiophlebia, Neopetaliidae, Aeshnidae, Cordulegastridae, Gomphidae, Petaluridae, and the libellulids Brachydiplax, Libellula and Trithemis. All other Libellulidae, Corduliidae and Synthemistidae possess hind legs which are longer but not twice as long as the abdomen.

97. Lateral spines or lobes on segment 5-9 in nymph: (0) absent; (1) present (Needham \& Westfall, 1955). Lateral spines on the last segments of the nymphal abdomen are present in the studied Aeshnidae, Austropetaliidae, and Petaluridae. In all other studied taxa possessing lateral abdominal spines these are not present from segments $5-9$.

98. Shape of distal margin of nymphal prementum: (0) with two apical, strong teeth flanked laterally by a rectangular tooth; (1) not as in (0). The distal margin of the nymphal prementum possesses two teeth flanked by a rectangular tooth in Neopetaliidae and Cordulegastridae (Fleck, 2011).

99. Nymphal molar lobes of left and right mandible: (0) moveable; (1) only left molar lobe moveable (flexible area present); (2) both molar lobes fixed (no flexible area present). The nymphal molar lobe is moveable on both mandibles in Epiophlebia and Gomphidae (Fleck, 2011), whereas it is only moveable on the left mandible in Chlorogomphidae (Fleck, 2011).

100. Dorsal spines or hooks on abdominal segments of nymph: (0) absent; (1) present (Needham \& Westfall, 1955). Dorsal projections on the nymphal abdominal segments are present in all studied Libellulidae, Macromiidae and Synthemistidae.

101. Number of dental folds in proventriculus: (0) 16; (1) 8; (2) 4. Fleck (2011) describes the proventriculus as follows: '. . . (it) is an internal bulbshaped structure of the alimentary canal making the junction between the foregut and the midgut. The part in contact with the lumen is essentially formed by longitudinal folds, the totality or a part of them carrying denticles placed on a sclerotized excrescence (= dental folds).' According to Fleck (2011) all Zygoptera (except Lestes) and Epiophlebia were coded as state (0) possessing 16 dental folds. Petaluridae (excluding Phenes) and Lestes possess a proventriculus with eight dental folds. All remaining Anisoptera have four dental folds in their proventriculus (Fleck, 2011).

102. Ventral dental folds of proventriculus with median elongated rasp-like dentition: (0) present; (1) absent. An elongated rasp-like dentition is present in all included Zygoptera, Epiophlebia, Chlorogomphidae, and Gomphidae (Fleck, 2011).

103. Internal part of the interantennal ridge (interantennal apodeme; Fig. 3): (0) absent; (1) present. An interantennal apodeme (iaa) originating at the interantennal ridge is present in Neopetaliidae, Aeshnidae, Gomphidae, Petaluridae (except Tachopteryx), Libellulidae (except 

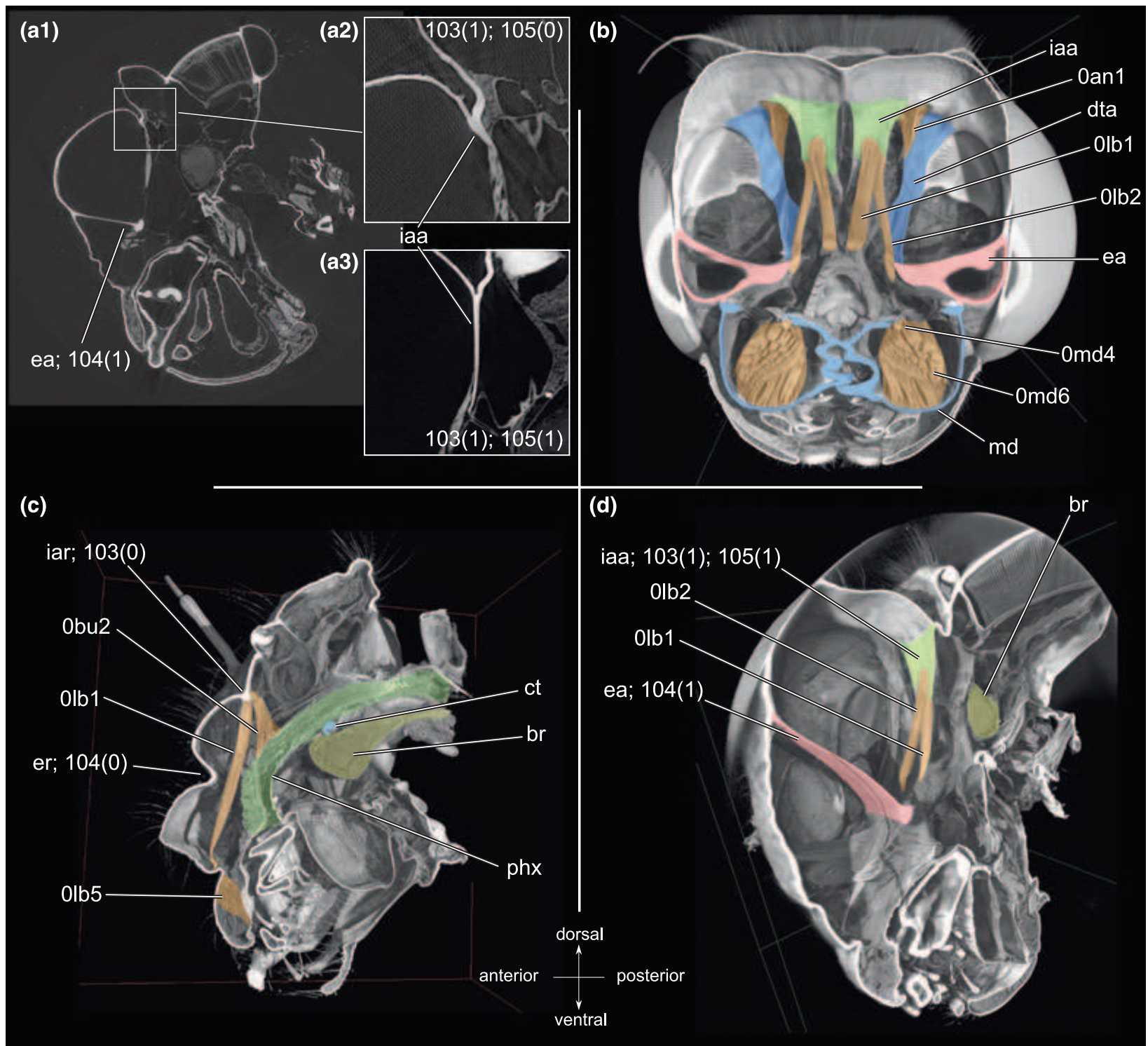

Fig. 3. General overview of the anatomic organization in Zygoptera and Anisoptera and illustration of characters $103-105$ (character states in brackets). (a1) Sagittal section of $L$. depressa at height of the left mandible illustrating the interantennal and the epistomal ridge and the respective apodemes. (a2) Detail of the interantennal ridge in L. depressa. (a3) Detail of the interantennal ridge in A. mixta. (b) Frontal section of A. mixta at height of the mandibular incisivi showing the interantennal apodemes and respective muscle attachments. (c) Sagittal section of $C$. virgo showing the absence of the interantennal and epistomal apodemes. (d) Sagittal section of A.mixta showing the epistomal and interantennal apodemes as well as muscle attachments. Abbreviations: 0lb1, M. frontolabralis; 0lb2, M. frontoepipharyngalis; 0lb5, M. labroepipharyngalis; 0md4, M. hypopharyngo mandibularis; 0md6, M. tentoriomandibularis lateralis inferior; 0bu2, M. frontobuccalis anterior; br, brain; dta, dorsal tentorial arm; ea, epistomal apodeme; er, epistomal ridge; iaa, interantennal apodeme; iar, interantennal ridge; md, mandible; phx, pharynx. (a) SR-microCT image, (b)-(d) volume renderings of SR-microCT image stacks. Images not to scale.

Zygonyx), Macromiidae and Corduliidae (except Procordulia). The situation in Chlorogomphidae and Synthemistidae is unclear (coded as '?'). The interantennal apodeme frequently serves as an attachment site for labral muscles (see characters 103 and 104).

104. Internal part of the epistomal ridge (epistomal apodeme; Fig. 3): (0) absent; (1) present. An epistomal apodeme (ea) originating at the epistomal ridge is present in all studied Anisoptera and absent in Epiophlebia and Zygoptera.

105. Internal part of the interantennal ridge (interantennal apodeme; Fig. 3): (0) short, no longer than one third the length of epistomal apodeme; (1) longer than one third of epistomal apodeme. The interantennal apodeme is short in Neopetaliidae, Gomphidae, Petaluridae, Libellulidae, Macromiidae, Corduliidae, and the 


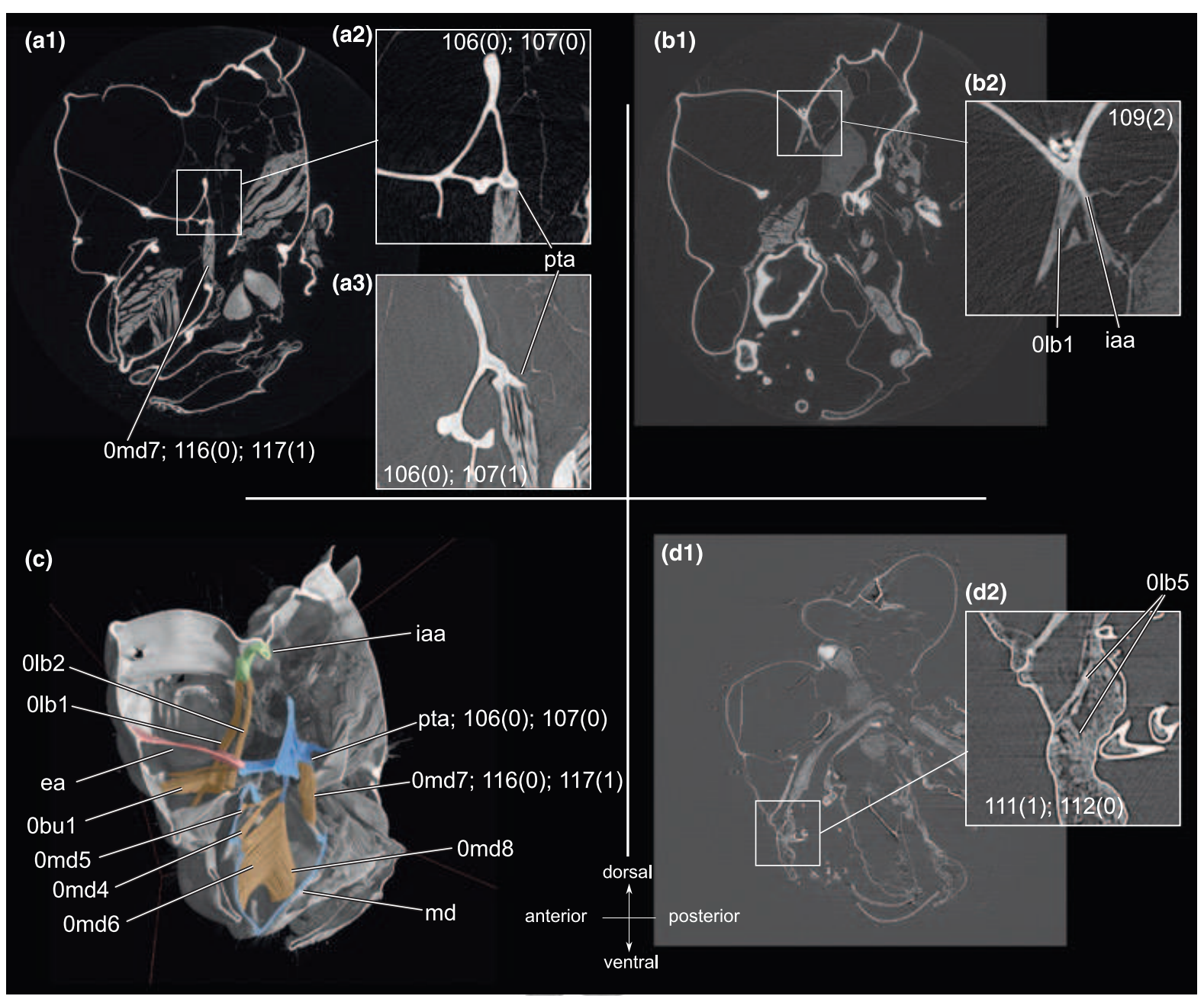

Fig. 4. Illustration of characters $106,107,109,111,112,116$ and 117 with SR-microCT data (character states in brackets). (a1) Sagittal section of $G$. pulchellus showing the posterior tentorial apodeme (pta) at the posterior base of the anterior tentorial arms and the location of M. tentoriomandibularis medialis superior (0md7). (a2) Detail of the pta in G. pulchellus. (a3) Detail of the pta in T. pryeri. (b1) Section of G. pulchellus showing M. frontoepipharyngalis (0lb2) originating at the interantennal ridge as well as on the interantennal apodeme. (b2) Detail of b1). (c) Sagittal section of $G$. pulchellus showing the configuration and location of the pta in relation to other head structures. (d1) 3D reconstruction of the labrum of $P$. gray showing the peculiar configuration of the M. labroepipharyngalis (0lb5). (a)+ (b)+ (d) SR-microCT images; (c) volume rendering of a SRmicroCT image stack. Abbreviations: 0lb1, M. frontolabralis; 0lb2, M. frontoepipharyngalis; 0lb5, M. labroepipharyngalis; 0md4, M. hypopharyngo mandibularis; 0md5, M. tentoriomandibularis lateralis superior; 0md6, M. tentoriomandibularis lateralis inferior; 0md7, M. tentoriomandibularis medialis superior; 0md8, M. tentoriomandibularis medialis inferior; 0bu1, M. clypeobuccalis anterior; ct, corpotentorium; ea, epistomal apodeme; iaa, interantennal apodeme; md, mandible; phx, pharnyx; pta, posterior tentorial apodeme. Images not to scale.

aeshnid Oligoaeschna. All other studied taxa exhibit an apodeme which is longer than one third of the epistomal apodeme.

106. Apodeme posteriorly of the anterior tentorial arm (attachment for 0md7; Fig. 4): (0) present; (1) absent. An apodeme serving as attachment site for $0 \mathrm{md} 7$ is present in all studied Aeshnidae, Gomphidae, Phyllopetalia, Anotogaster and all Petaluridae except Uropetala.

107. Apodeme posteriorly of the anterior tentorial arm (attachment for 0md7; Fig. 4): (0) proximally in contact with the base of the anterior tentorial arm; (1) seperated at the entire length. The apodeme for attachment of 0md7 is proximally in contact with the anterior tentorial arms in Aeshnidae, Gomphidae, Anotogaster, Phenes and Tachopteryx.

108. M. tentorioscapalis lateralis (0an3): (0) present; (1) absent. Present in Calopteryx, Aeshnidae, Corduliidae, Zonophora (Gomphidae), Libellula and Sympetrum (both Libellulidae). Absent in all other studied taxa.

109. Origin of M. frontolabralis (0lb1; Fig. 4): (0) at the interantennal ridge; (1) at the interantennal apodeme; (2) partly at the interantennal ridge, partly at the interantennal apodeme. The M. frontolabralis (0lb1) originates at the interantennal ridge in all Zygoptera, Epiophlebia, 


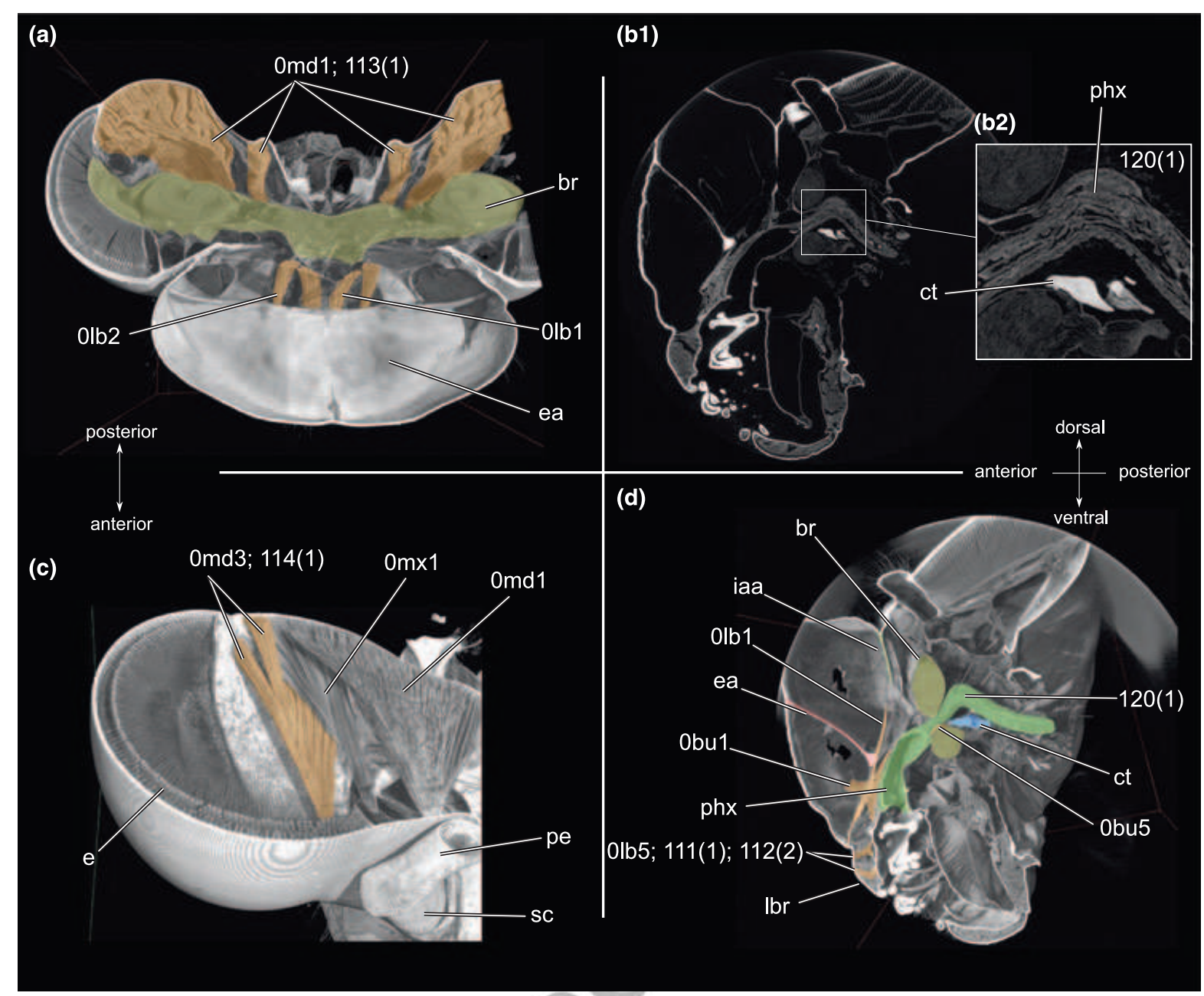

Fig. 5. Illustration of characters 111-114 and 120 with SR-microCT data (character states in brackets). (a) Transversal section of G. pulchellus showing the origins of M. craniomandibularis internus (0md1). (b1) Sagittal section of A. mixta showing the peculiar progression of the pharynx at height of the corpotentorium. (b2) Detail of (b1). (c) Transversal section of $C$. virgo showing the second origin of the M. craniomandibularis externus (0md3). (d) Sagittal section of A. mixta showing the origins and insertions of M. labroepipharyngalis (0lb5) and the progression of the pharynx. Abbreviations: 0lb1, M. frontolabralis; 0lb2, M. frontoepipharyngalis; 01b5, M. labroepipharyngalis; 0md1, M. craniomandibularis internus; 0md3, M. craniomandibularis externus; 0bu1, M. clypeobuccalis; br, brain; ct, corpotentorium; ea, epistomal apodeme; iaa, interantennal apodeme; lbr, labrum; pe, pedicellus; phx, pharnyx; sc, scapus. Images not to scale.

Neopetaliidae, Austropetaliidae, Tachopteryx and Procordulia. The muscle originates at the interantennal ridge in all studied Aeshnidae, Cordulegastridae, Petaluridae (except Tachopteryx), Libellulidae, Macromiidae and Cordulia (Corduliidae).

110. Origin of M. frontoepipharyngalis (0lb2): (0) partly on the interantennal ridge, partly on the interantennal apodeme; (1) only on the interantennal apodeme; (2) only on the interantennal ridge. The $\mathrm{M}$. frontoepipharyngalis (0lb2) originates partly on the interantennal ridge in all Zygoptera, Epiophlebia, and Gomphidae. It originates completely on the interantennal apodeme in Neopetaliidae, Aeshnidae, Petaluridae (except Tachopteryx), Libellulidae, Macromiidae, Cordulia and Sonjagaster.
111. M. labroepipharyngalis (0lb5; Fig. 5+ Fig. 6): (0) one muscle bundle; (1) two distinct muscle bundles. The M. labroepipharyngalis (0lb5) is split up into two distinct muscle bundles in Aeshnidae and the corduliid Procordulia.

112. M. labroepipharyngalis (0lb5; Figs 4 and 5): (0) originating directly ventral of the labral ridge; (1) originating centred on the labium; (2) one bundle centred on the labium, the other directly ventral to the labral ridge. The M. labroepipharyngalis (0lb5) originates directly ventral of the labral ridge in Neopetaliidae, Cordulegastridae, Corduliidae and Phenes (Petaluridae). The muscle originates further ventral in the centre of the labium in all studied Zygoptera, Austropetaliidae, Gomphidae and all remaining Petaluridae. 


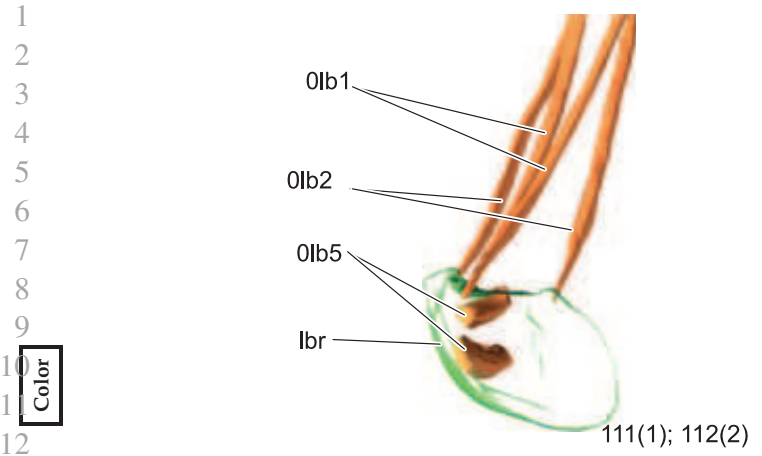

Fig. 6. 3D reconstruction of the labrum and associated muscles of $A$. mixta illustrating the double origin of M. labroepipharnygalis (0lb5). Abbreviations: 0lb1, M. frontolabralis; 0lb2, M. frontoepipharyngalis; 0lb5, M. labroepipharyngalis; lbr, labrum.

113. M. craniomandibularis internus (0md1; Fig. 5): (0) without second origin; (1) with two clearly seperated, well-defined origins. The main adductor of the mandible (0md1) possesses a clearly separated second origin in all studied Gomphidae, Libellulidae, Corduliidae and the petalurid Tachopteryx.

114. M. craniomandibularis externus (0md3; Fig. 5): (0) with one origin; (1) with two clearly separated, well-defined origins. The abductor of the mandible $(0 \mathrm{md} 3)$ possesses a clearly separated second origin further proximal in all studied Gomphidae, Neopetaliidae, Calopteryx, Epiophlebia, Oligoaeshna and Tachopteryx.

115. Origins of $\mathrm{M}$. craniomandibularis externus (0md3): (0) only ventral of $\mathrm{M}$. craniomandibularis internus (0md1) and M. craniolacinialis $(0 \mathrm{mx} 2)$; (1) one origin ventral of $0 \mathrm{md} 1$ and $0 \mathrm{mx} 2$, one dorsal of $0 \mathrm{mx} 2$; (2) one origin ventral of $0 \mathrm{md} 1$, one origin dorsal of $0 \mathrm{md} 1$. The origin of the abductor of the mandible $(0 \mathrm{md} 3)$ is ventral of the 0md1 in all studied Zygoptera (except Calopteryx), Aeshnidae, Austropetaliidae, Cordulegastridae, Libelluloidea and all Gomphidae except Gomphus. If composed of two bundles this muscle originates with one bundle ventral of $0 \mathrm{md} 1$ and with the other one dorsal of $0 \mathrm{md} 1$ in Epiophlebia, Neopetaliidae and Gomphus.

116. M. tentoriomandibularis medialis superior (0md7; Fig. 4): (0) present; (1) absent. The M. tentoriomandibularis medialis superior (0md7) is absent in Calopteryx, Epiophlebia, Aeshnidae, Libellulidae, Corduliidae and Macromiidae.

117. Insertion of $\mathrm{M}$. tentoriomandibularis medialis superior (0md7; Fig. 4): (0) on the ventral side of the anterior tentorial arms near the base; (1) on separate apodeme posterior of the anterior tentorial arms; (2) on the posterior side of the dorsal tentorial arm base. In those taxa where the $0 \mathrm{md} 7$ is present its insertion varies. It inserts near the base of the anterior tentorial arm on its ventral side in Lestes, on a separate apodeme posterior of the anterior tentorial arms in Gomphidae and all Petaluridae (except Uropetala), and on the posterior side of the base of the dorsal tentorial arms in all remaining
Zygoptera, Austropetaliidae, Cordulegastridae and the petalurid Uropetala.

118. M. craniocardinalis ( $0 \mathrm{mx} 1)$ : (0) with only one origin; (1) with two clearly separated, well-defined origins. The M. craniocardinalis $(0 \mathrm{mx} 1)$ possesses a second origin in Uropetala (Petaluridae) and Zygonyx (Libellulidae).

119. M. tentoriobuccalis anterior (Obu5): (0) present; (1) absent. The M. tentoriobuccalis anterior (Obu5) is absent in all studied Aeshnidae except Oligoaeschna.

120. Location of pharynx (Figs 5 and 6): (0) in touch with the corpotentorium ; (1) not in touch with the corpotentorium. The pharynx is not in contact with the corpotentorium in all studied Aeshnidae, Cordulegastridae, Lestes and Tachopteryx.

\section{Phylogenetic results}

Phylogenetic analysis of the morphological data (Fig. 7) resulted in 4680 equally parsimonious trees. In the following we will only focus on the interfamily relationships. Generally, all currently recognized anisopteran families except Corduliidae were recovered as monophyletic. In a strict consensus (length $=409 ; \mathrm{Ci}=39 ; \mathrm{Ri}=83$ ) Epiophlebia is recovered as sister to all Anisoptera (= Epiprocta fide Lohmann (1996)) with high support (BR11/PB99/PP1.0). The head morphology of Epiprocta is characterized by an enlarged frons and vertex $(3: 1 ; 12: 0,1,2,4,5)$, a globular shape of the head (9:0), and a distance between the eyes never greater than their own width $(10: 0,2,3)$. Apomorphies related to the wing are the relative size of the anterior and posterior lobes of the FxC sclerite (14:1), the general shape of the wing (17:1), the position of the arculus (24:1), the wing position at rest (52:0), and the obliquity of the thorax (64:0). The shape of the anterior hamules (68:3), presence of an epiproct (74:0), and the configuration of the paraprocts (76:0) are potential apomorphies of Epiprocta related to the copulatory system, whereas presence/absence of nymphal caudal (83:0) and rectal gills (84:1), and the absence of nymphal raptorial setae (86:0) are the larval characters supporting monophyletic Epiprocta.

Monophyletic Anisoptera (BR16/PB100/PP1.0) split into monophyletic Gomphidae (BR5/PB94/PP.53) which are sister to all remaining Anisoptera. Unique head characters of Anisoptera are the arrangement of the anteclypeus and postclypeus (0:1) and the presence of an interantennal (103:1) and epistomal apodeme (104:1). Wing characters are the shape of the BxC sclerite (13:2), the origin of the MP vein (23:3), the structure of the quadrangle $(32: 2 ; 37: 2)$, presence of a costal nodal kink (39:1), a membranule (40:1), a secondary CuP-vein (51:1), and an anal triangle (54:1) as well as the width of the MA-MP field (48:1). Further apomorphies are the segmentation of the vesica spermalis $(71: 1)$ and the presence of auricles $(78: 1)$.

Gomphidae are supported by one head apomorphy, the peculiar origin of the M. frontolabralis (0lb1; 109:2) and several nymphal characters: the structure of the antennae (89:1; 
(a)
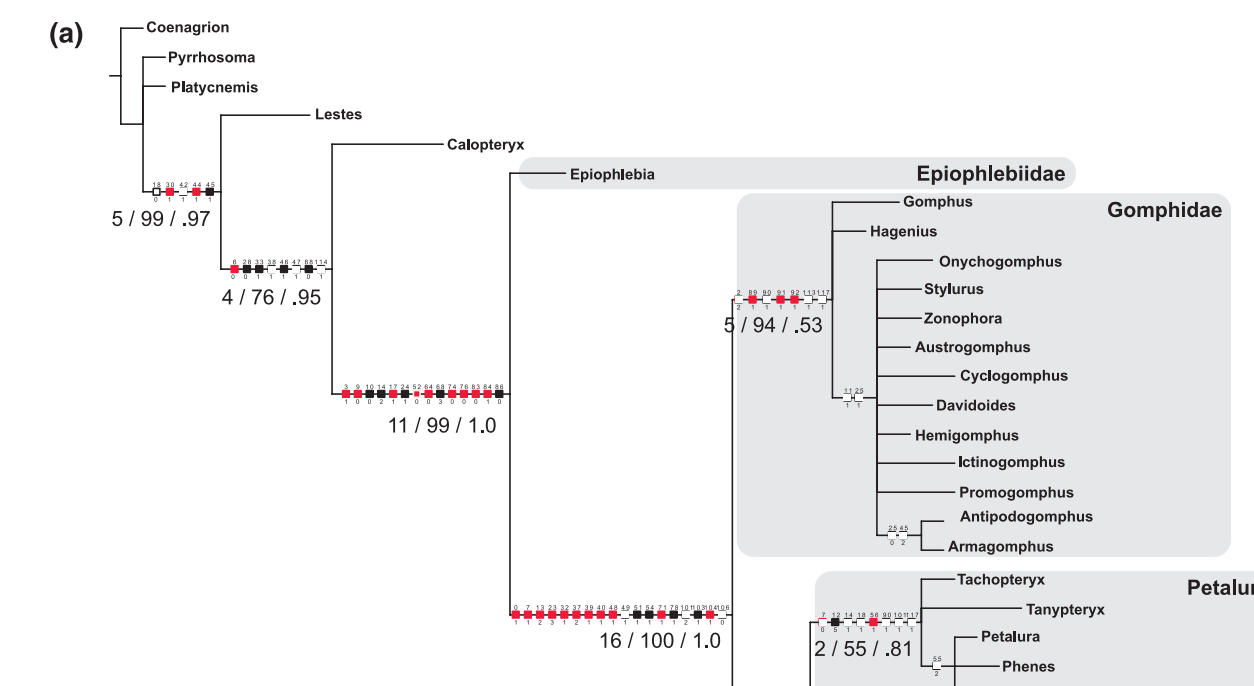

(b)

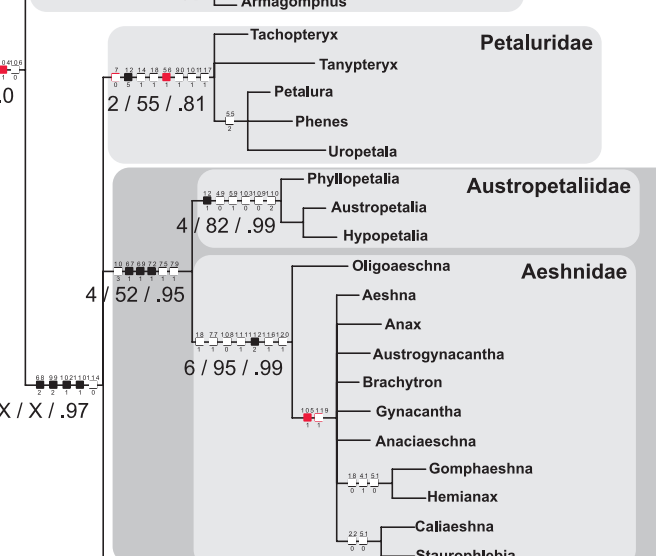

\section{Aeschnomorpha}
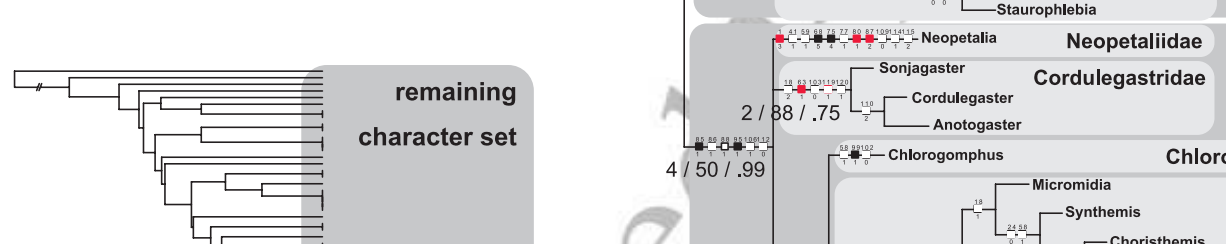
$4 / 50 / .99$

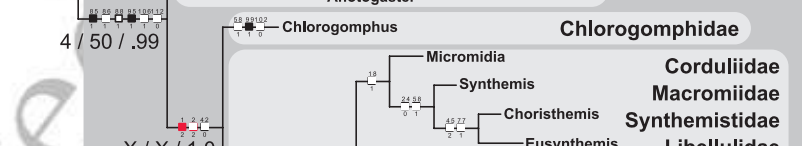

Chlorogomphidae

Libelluloidea

$x / x / 1.0$
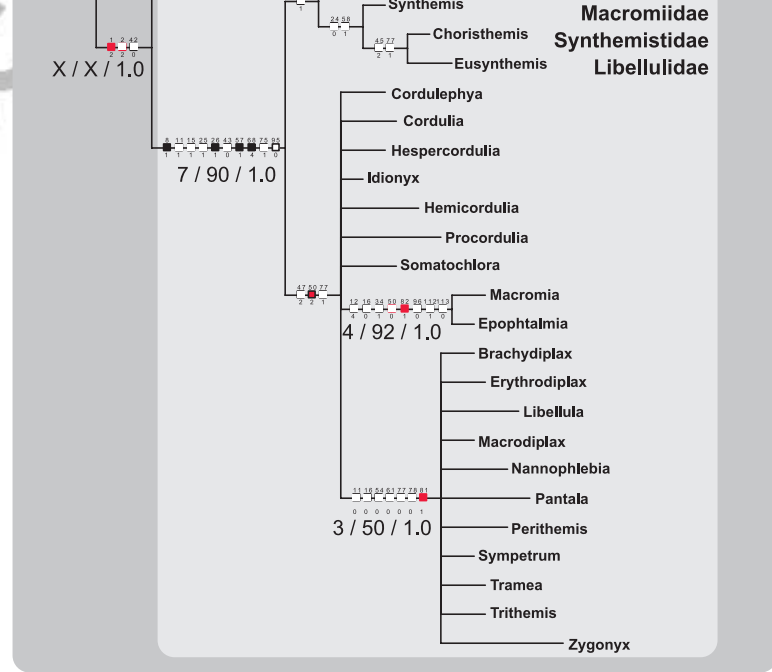

Fig. 7. Strict consensus (length $=412 ; \mathrm{CI}=39 ; \mathrm{RI}=83$ ) of the 4750 equally parsimonious trees derived from maximum parsimony analysis of the complete morphological dataset. Support values from maximum parsimony and Bayesian inference are mapped on the tree. Bremer support $=$ first node value, bootstrap support $=$ second node value, posterior probability $=$ third node value. $X$ indicates Bremer support below 2, bootstrap support below 50 or a posterior probability below 0.7 , respectively. Character numbers are indicated above squares, state changes below. Grey squares indicate the characters which clustered in clique 1. (b) UPGMA clustering of the pairwise excess index matrix calculated in PAUP. Clustered characters are indicated by a vertical terminal line. For a detailed tree with all characters mapped see File S2. 
91:1) and mesotarsi (92:1). All other Anisoptera group together through the following synapomorphies: the configuration of the hamules (68:2), the fixed molar lobes of the nymphal mandible (99:2), the loss of rasp-like dentitions in the ventral dental folds of the proventriculus (102:1), and origin of the M. frontoepipharyngalis (0lb2) at the interantennal apodeme (110:1).

The position of Petaluridae (BR2/PB55/PP81) could not be resolved with the available data. Apomorphies supporting monophyletic Petaluridae are the shape of the vertex and the location of the ocelli (12:5) and the length of the pterostigma (56:1). Austropetaliidae are the sister group of Aeshnidae (BR4/PB52/PP.95) through the orientation of the anterior hamuli $(67: 1)$, the structure of the anterior lamina (69:1) and vestigial posterior hamules (72:1). Monophyletic Austropetaliidae (BR4/PB82/PP.99) are supported by the shape of the vertex and the location of the ocelli $(12: 1)$, monophyletic Aeshnidae (BR6/PB95/PP.99) by the origin of the bundles of the M. labroepipharyngalis (0lb5; 112:2). Libelluloidea (BR4/PB50/PP.99) are supported by the scoopshaped form of the labium $(85: 1)$ and the toothed distal margin of the prementum (95:1) with Neopetalia as sister to all remaining Libelluloidea. Potential autapomorphies of Neopetalia are the triangular shape of the labial palp (1:3), the U-shaped external hamules (68:5), the undivided epiproct (75:4), the ventroapical tufts of long hairs on abdominal segments 5-8 (80:1), and the number of raptorial setae (1-3) on the prementum $(87: 2)$. The position of Cordulegastridae (BR2/PB88/PP.75) inside Libelluloidea is unresolved. The data support a basal position and the monophyly of the group through the quadrangular form of the male mesotibial spines (63:1). Chlorogomphidae is recovered as the sister group of Corduliidae, Synthemistidae, Macromiidae and Libellulidae (BR7/PB 90/PP1.0) which is supported by the well-developed anal loop (50:2). Corduliidae are polyphyletic, Macromiidae (BR4/PB92/PP1.0) are supported by the presence of horns between the eyes $(82: 1)$, Libellulidae by the triquetral abdomen (81:1).

Concerted convergence analysis (CCA) of the morphological dataset yielded one significant clique (Fig. 7b) containing 51 characters (the clique threshold size for significance was 24 characters). Parsimony analysis of the characters contained in this clique yielded 37 equally parsimonious trees. In a strict consensus (Fig. 8a; length $=70 ; \mathrm{Ci}=91 ; \mathrm{Ri}=98$ ) Anisoptera are monophyletic with Oligoaeschna and Petaluridae branching off first. Paraphyletic Austropetaliidae group together with Neopetalia, 'Aeshnidae' with monophyletic Cordulegastridae. Gomphidae are the sister group to all remaining Libelluloidea, Synthemistidae and Corduliidae which are retrieved as paraphyletic groups.

Parsimony analysis of the remaining character set excluding clique 1 produced 3750 equally parsimonious trees. The strict consensus (Fig. 8b, length $=398 ; \mathrm{Ci}=24 ; \mathrm{Ri}=73$ ) resulted in Gomphidae as sister group to all remaining Anisoptera. 'Petaluridae' are polyphyletic; Austropetaliidae and Aeshnidae are sister groups. Libelluloidea are monophyletic; however, the position of 'Cordulegastridae', Chlorogomphidae and

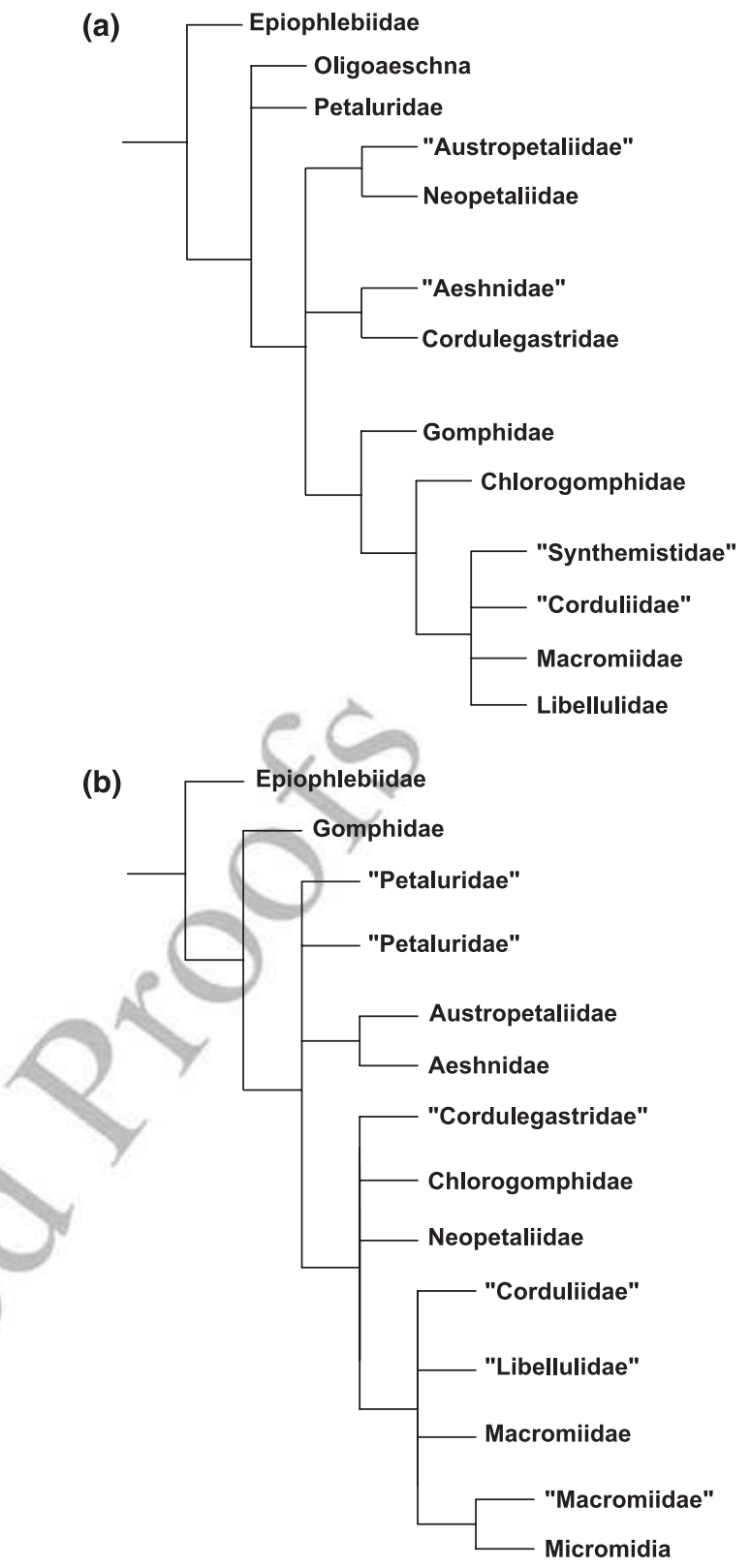

Fig. 8. Phylogenies calculated from the significant clique of characters (a) and from the remaining characters (b) of the morphological data matrix. Parsimony analyses in TNT, 1000 heuristic searches with random addition of taxa (TBR branch swapping). (a) Strict consensus of 37 trees; 50 characters; tree length $=70 ; \mathrm{RI}=98 ; \mathrm{CI}=91$. (b) Strict consensus of 3750 trees; 69 characters; tree length $=398$; RI $=73$; $\mathrm{CI}=24$. Para- or polyphyletic groups are put in quotation marks.

Neopetalia could not be resolved, whereas 'Corduliidae', 'Libellulidae' and Macromiidae form a clade. The character distribution among the clique and the remaining characters (Figs 9 10) showed a higher number of head and thorax characters in the clique compared with the number of head characters in the complete matrix, whereas fewer anatomical characters are represented in the clique. 


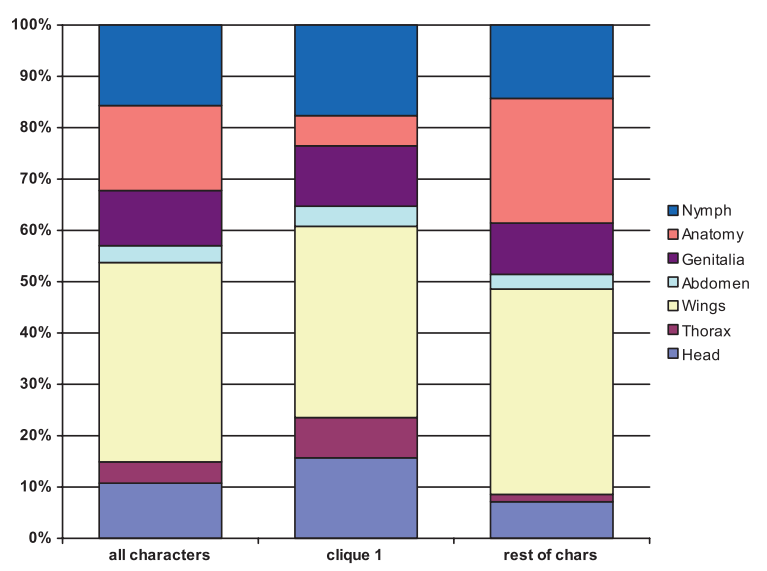

Fig. 9. Distribution of characters in the complete data matrix (left bar) and in the derived character clique (middle bar) and in the remaining amount of characters (right bar).

\section{Discussion}

\section{Epiophlebiidae is the sister group to Anisoptera}

A study based on the morphology of the ovipositor of Epiophlebia (Matushkina, 2008a) stated that Epiophlebia exhibits some similarities with the ovipositor organization in Zygoptera, and Dumont etal. (2010) recovered Epiophlebia as the sister group to Cordulegastridae (EC hypothesis) based on the analysis of $18 S, 5.8 S$ and ITS1 and two sequences. Klass (2008), in an overview of ovipositor-bearing Odonata, found no abdominal characters resolving the position of Epiophlebia.

From a morphological perspective (Blanke et al., 2012a) the abovementioned groupings seem to be unlikely and are not found in the phylogenetic analysis of the present study. A CTR of the EC hypothesis resulted in a tree 17 steps longer than the most parsimonious strict consensus with multiple homoplastic changes for Epiophlebiidae and Cordulegastridae (Fig. 11). Also, after concerted convergence analysis (CCA) Epiophlebia remains sister group to Anisoptera. Most other molecular studies also support this position (Bybee et al., 2008; Fleck etal., 2008b; Letsch etal., 2009).

\section{Gomphidae is the sister group of all remaining Anisoptera}

Gomphidae as sister group to all other Anisoptera was always recovered and the family retained its position after concerted convergence analysis (CCA). A sister group relationship of Gomphidae with all remaining Anisoptera was first proposed by Carle (1982). In the present study this position is supported by the internal and hooked-like structure of the anterior hamules (68:3), the moveable molar lobes of the left and right mandible (99:0), the presence of rasp-like dentitions on the ventral dental folds of the proventriculus (102:0; Fleck (2011)), and the peculiar origin of the M. frontoepipharyngalis (0lb2) on the interantennal ridge as well as on the interantennal apodeme (110:0; Fig. 4). Although these character states are plesiomorphic because they are shared with Epiophlebiidae, Gomphidae share the states of characters $0,7,13,23,32$, 37, 39, 40, 48, 51, 54, 71, 78, 103 and 104 with Anisoptera (see Fig. 7 and S2 [?] for details). The remaining Anisoptera except Gomphidae are supported by several potential autapomorphies: the internal and folded anterior hamules $(68: 2)$, the fixed molar lobes of the mandibles (99:2), the absence of rasplike dentitions on the ventral dental folds of the proventriculus (102:1), and the origin of M. frontoepipharyngalis solely on the interantennal apodeme (110:1).

A recent molecular study using mitochondrial sequence data and secondary RNA structure information suggested a clade Aeshnoidea comprised of Gomphidae, Petaluridae, Austropetaliidae and Aeshnidae (Fleck etal., 2008b). With the exception of Neopetalia, which was transferred to Libelluloidea (Carle \& Louton, 1994), this clade has already been proposed by Fraser (1957). However, this pre-Hennigian classification was based on symplesiomorphies. Fleck etal. (2008b) has already pointed out that a hypothetical clade Aeshnoidea is backed up by only one putative synapomorphy, the fusion of sternites and postpleurites in larval abdominal segments 9. Instead, the grouping Aeshnoidea would imply an independent reduction of the ovipositor in Gomphidae and libelluloid lineages. A position of Gomphidae within 'Aeshnoidea' is equally not supported by any character of the present matrix and requires one additional step in CTR (Fig. 11).

Other morphological (Bechly, 1996; Lohmann, 1996) and molecular (Misof etal., 2001) studies proposed a sister group relationship Gomphidae + Libelluloidea which was not favoured by Carle (1995), because he considered larval characters and structures related to the male copulatory apparatus as homoplastic. Again, a relationship of Gomphidae with Libelluloidea is not supported by any character of the present matrix and a CTR enforcing this relationship requires four additional steps (Fig. 11). In our study the position of Gomphidae as sister to all other Anisoptera was also corroborated by CCA and this results in an additional putative synapomorphy for the remaining Anisoptera, the internal and folded structure of the anterior hamules (68:2).

\section{Aeshnoidea and Libelluloidea are monophyletic}

The present study supports Aeshnomorpha, Aeshnidae + Austropetaliidae. Besides the characters presented herein, monophyletic Aeshnidae are supported by the welldeveloped median and radial planates of the wings (Bechly, 1996; Carle, 1996; Lohmann, 1996). In contrast to Bechly we do not consider the well-developed 'interocellar lobe' (=vertex) as an autapomorphy of Aeshnidae, because several taxa, especially Libellulidae and Cordulegastridae also possess a well-developed vertex.

Aeshnomorpha are well supported by molecular and morphological studies, since the establishment of Austropetaliidae and placement of Neopetalia inside Libelluloidea (Carle \& Louton, 1994). Neopetalia only superficially resembles Austropetaliidae in wing colour pattern (Garrison et al., 2006)

AQ 18 
(a)

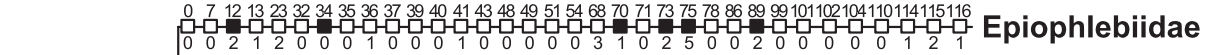

(1)

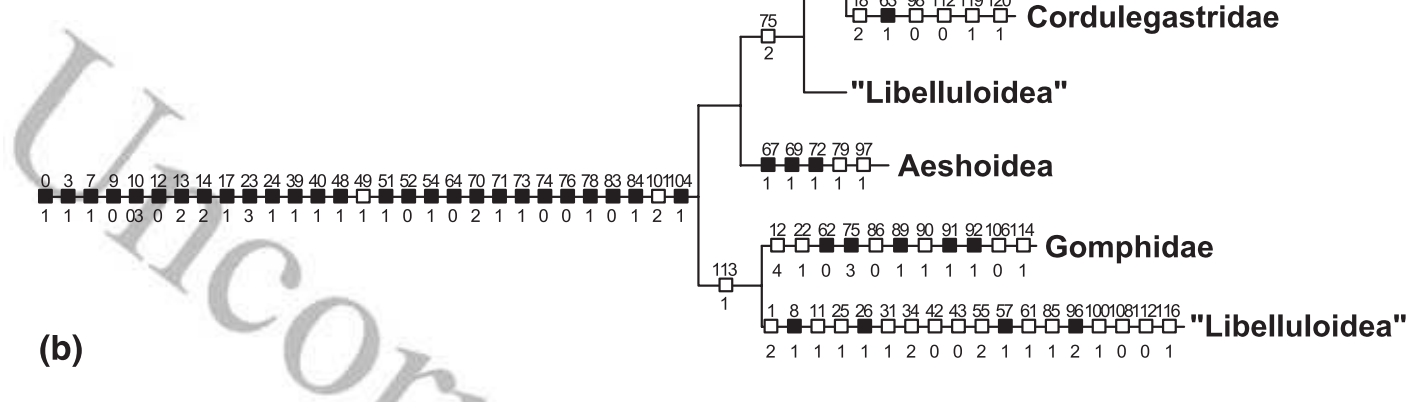

(b)

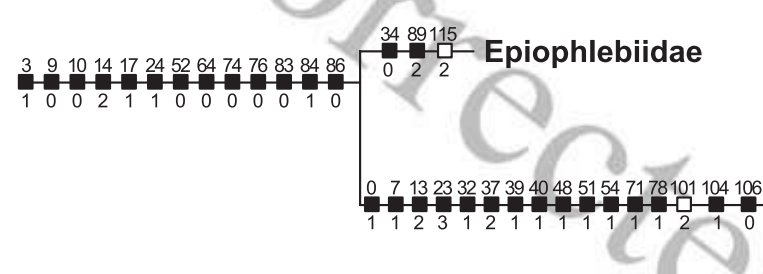

(c)

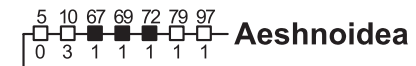

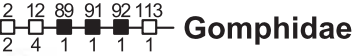

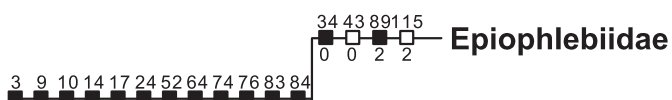

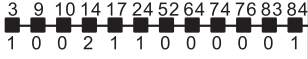

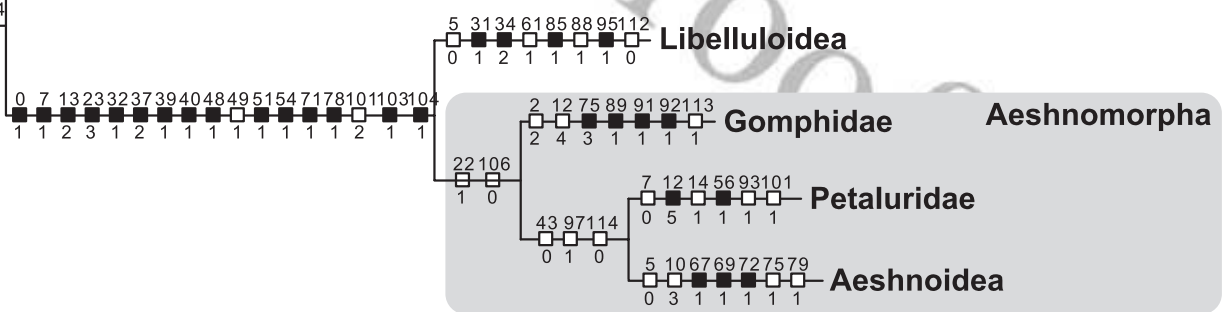

Fig. 10. Character optimizations on the CTRs (suboptimal tree resolutions) of the three enforced hypotheses concerning the deep relationships inside Anisoptera. (a) Strict consensus enforcing a sister group relationship of Ephiophlebiidae + Cordulegastridae (EC hypothesis (Dumont et al., 2010); length $=454$ steps, CI $=35$, RI $=80$ ). (b) Strict consensus with enforced Aeshnomorpha as sister to all remaining Anisoptera (AA hypothesis (Letsch et al., 2009); length = 416 steps, CI = 38, RI = 83). (c) Strict consensus with enforced Aeshnoidea as sister to Libelluloidea (AL hypothesis (Fleck et al., 2008b); length $=415$ steps, $\mathrm{CI}=39, \mathrm{RI}=83$ ). Nonhomoplasious character changes are indicated with black squares, homoplasious characters with white squares. Trait numbers are indicated above squares, state changes below. For trait reference see Table S3. 


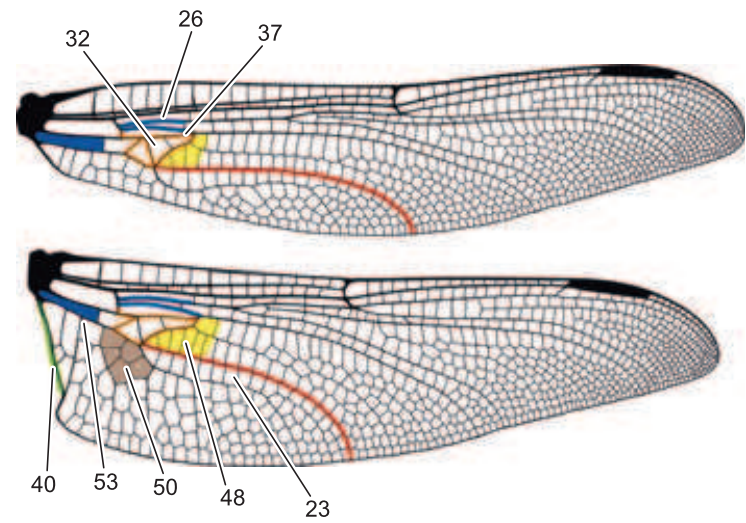

$23 \mathrm{MP}$ origin

$26 \mathrm{RP}$ and MA divergence

32 Division of quadrangle

37 Distal angle of quadrangle

40 Presence of membranule

48 Width of MA-MP field immediately distal of discoidal vein

50 Form of anal loop

53 Number of crossveins basal of Cu crossing

Fig. 11. Illustration of a part of the wing characters which clustered in the clique based on the wing of Hagenius brevistylus (Odonata: Gomphidae). For a complete overview of the characters which clustered in the clique please refer to Table S5. For a complete character list including the character numbering of Rehn (2003) and Bybee etal. (2008) see File S3.

and a quadrate epiproct (Carle et al., 2008). Accordingly, similarities between Aeshnidae and Libellulidae like the contiguous eyes and the structure of the anal loop are homoplasies (see also Carle etal. (2008)).

Our analyses support monophyly of Libelluloidea albeit with low bootstrap support. The result is in line with many molecular studies, where Libelluloidea are recovered with low support values (Fleck etal., 2008b; Letsch etal., 2009). Morphologically the clade is supported by the spoon-shaped labial mask of the nymph as was already proposed by others (Carle, 1995; Lohmann, 1996). Still, convincing imaginal synapomorphies are lacking and the anatomical characters included here provide no further support for this clade.

\section{The position of Petaluridae remains unresolved}

The position of Petaluridae is not robustly resolved in other studies and could not be resolved in the present study either. Molecular studies recovered the family either as sister to Gomphidae (Misof etal., 2001), as sister to Aeshnomorpha (Fleck etal., 2008b), as sister to Libelluloidea (Carle etal., 2008), or as sister to Chlorogomphidae + Cordulegastridae (Bybee etal., 2008).

Using wing characters, Trueman (1996) proposed Petaluridae as sister to all remaining Anisoptera as did Rehn (2003) based on characters of the whole body. Pfau (1991) focused on genitalic characters and proposed a sister group relationship of Petaluridae to a clade consisting of Gomphidae, Cordulegastridae and Petaluridae. Recently, Fleck (2011) hypothesized a sister group relationship of Petaluridae with
Aeshnomorpha based on the structure of the mandibles, the proventriculus and the anal pyramid in nymphs, as well as the styli of the ovipositor and the terminalia. However, as the author himself stated, these characters are prone to convergence or their status in certain taxa is unclear. We adopted those characters for which homology hypotheses are clear and taxon sampling was sufficient (characters 94, 98, 99, 101, 102) but they did not serve to clarify the position of Petaluridae.

\section{Potential homoplasy in head characters}

CCA of the complete dataset yielded one character clique of significant size (Fig. 7b). This clique contained a high amount of head characters whereas the amount of anatomical characters is reduced compared to the character distribution in the remaining matrix (Fig. 9). Head characters of the clique are related mainly to the general head structure and the configuration of the labium. The ante- and postclypeus facing anteriorly $(0: 1)$, the grossly enlarged shape of the frons (3:1), and presence of an epistomal apodeme (ea, 104:1) are characters influencing the general globular shape of the head (9:0). According to the present CCA the characters seem to be correlated to each other and should therefore be excluded from further analyses. The globular head shape already accounts for the modifications of certain substructures (clypeus, frons, ea).

Wing base characters evolved concerted convergent

The number of wing characters did not differ significantly between the three datasets (original matrix, clique and remaining subset); however, character distribution in the clique is interesting. A high amount of characters ( 8 out of $19=42 \%$ ) are related to the wing base (Fig. 11), specifically to the quadrangle area $(23 / 26 / 32 / 37 / 48)$ and the anal loop area $(40 / 50$ and probably 53).

Wootton \& Kukalová-Peck (2000) already identified two areas in the palaeopteran wing - the leading edge-nodus complex and the arculus - which are responsible for the flight capabilities in modern Odonata. Based on this Bybee etal. (2008) mapped wing characters onto their inferred tree and identified the pterostigma-nodal brace complex as well as the costal wing base and costal-ScP junction complex as areas where key innovations during the transition from ancient flight styles only represented by fossils to modern' flight styles took place (modern including all extant odonate groups plus fossil Tarsophlebiidae). According to the authors, these complexes also showed convergent evolution (Bybee etal., 2008).

Concerning extant taxa [+ Tarsophlebiidae?], we propose that especially the wing base venation may have evolved concerted convergent (Fig. 11). Changes in the origin of the MP vein (23) and the width of the MA-MP field (48), as well as the divergence of the RP and MA veins (26) and several characters of the quadrangle $(32,37)$, anal loop (50), and membranule (40) seem to be correlated to each other. However, we judge it too early to map these wing characters on the strict consenus tree reconstructed for two reasons: first, wing

$$
\begin{aligned}
& 1 \\
& 2 \\
& 3 \\
& 4 \\
& 5 \\
& 6 \\
& 7 \\
& 8 \\
& 9
\end{aligned}
$$


character state shifts within families are present; and second, the resolution within families using the present character set is too low. This hampers estimation of a wing venation pattern common, for example, to all Gomphidae (compare, e.g., presence of an anal loop in different taxa of Gomphidae and Petaluridae, or the changing division of the quadrangle within all families). Therefore, a drastically increased taxon sampling within studies focused on reconstructions of wing venation patterns among anisopteran families is warranted.

The present CCA analysis shows that the amount of concerted convergence is high in the wing base area (Fig. 11). To further corroborate these results by an independent dataset, functional analyses are needed simulating the effect of single vein changes on the vein system. These functional analyses can also be done with the wing venation pattern of fossil taxa, because the wing preservation status is often excellent (Bechly, 1995).

\section{Conclusion}

A sister group relationship of Gomphidae + remaining Anisoptera is most parsimonious when taking into account all currently available characters. Analyses of concerted convergence reveal the presence of a single clique of characters which support an alternative but implausible tree. Tree reconstruction using the remaining character set corroborated the position of Gomphidae. Analysis of the significant clique showed that especially head and - to a minor extent thorax characters need extensive re-evaluation with regards to possible interdependence of characters. Moreover, characters related to wing venation showed an unusual distribution among the significant character clique. Results suggest that especially the wing base venation may harbour concerted convergent characters.

Character distribution analysis shows that characters of internal anatomy do not group into cliques, meaning that interdependencies are not likely for these characters. Further studies, especially those focused on the internal anatomy of the copulatory apparatus, will likely yield new phylogenetically informative characters which can be analysed with the analysis framework presented herein.

\section{Supporting Information}

Additional Supporting Information may be found in the online version of this article under the DOI reference:

$10.1111 /$ syen. 12012

Table S1.Taxon sampling and literature sources used. Scanning parameters at the microCT facilities (DESY, PSI, SI) are given in the following order: first value, energy $(\mathrm{keV})$; second value, magnification; third value, pixel size $(\mu \mathrm{m})$.

Table S2. Homologized head musculature between studied taxa and literature.
Table S3. Character matrix used for phylogenetic analysis including character numbers from the literature resources, nd the character numbers of the significant clique characters and the remaining character set.

Table S4. Pairwise excess index matrix showing an overview of the amount of pairwise compatible characters and the PEI values in case of incompatibility.

Table S5. Excess distribution of the 121 morphological characters on the molecular hypothesis. Most of the characters have a good fit on the molecular tree (excess 0 and 1).

File S1. Complete list of morphological characters used.

File S2. UPGMA clustering (see also Fig. 7b) of the dissimilarity values calculated in the pairwise excess index matrix showing all character numbers of the morphological data matrix. Clustered characters are indicated by a vertical terminal line. The significant clique and the remaining character subset used for subsequent tree reconstruction (Fig. 8) are indicated by grey boxes.

File S3. RaxML analysis of the molecular data showing unsupported Aeshnomorpha, Petaluridae + Gomphidae and Chlorogomphidae + Cordulegastridae.

\section{Acknowledgement}

Ryuchiro Machida kindly provided specimens of E. superstes. The morphological data were mainly gathered at the Deutsches Elektronen Synchrotron (DESY, Hamburg, Germany) with support from grants I-20080169 and I-20090211, the PaulScherrer Institut (PSI, Villigen, Switzerland) through grant no. 20110069 and at the Steinmann Institut (Bonn, Germany) which is gratefully acknowledged. We sincerely thank Barbara Holland who provided useful assistance with the implementation of her concerted convergence analysis and Jessica Ware who gave useful comments throughout the preparation of this paper.

\section{References}

Ballare, E.F. \& Ware, J.L. (2011) Dragons fly, biologists classify: an overview of molecular odonate studies, and our evolutionary understanding of dragonfly and damselfly (Insecta: Odonata) behavior. International Journal of Odonatology, 14, 137-147.

Bechly, G. (1995) Morphologische untersuchungen am Flügelgeäder der rezenten libellen und deren stammgruppenvertreter (Insecta; Pterygota; Odonata) unter besonderer berücksichtigung der phylogenetischen systematik und des grundplanes der Odonata. Petalura, 1, 1-341.

Bechly, G. (1996) Morphologische untersuchungen am Flügelgeäder der rezenten libellen und deren stammgruppenvertreter (Insecta; Pterygota; Odonata) unter besonderer berücksichtigung der phylogenetischen systematik und des grundplanes der Odonata. Petalura, 2, 1-402. 
Beckmann, F., Herzen, J., Haibel, A., Müller, B. \& Schreyer, A. (2008) High density resolution in synchrotron-radiation-based attenuation-contrast microtomography. Proceedings of SPIE, 7078, 70781D-70783D.

Blanke, A., Beckmann, F. \& Misof, B. (2012a) The head anatomy of Epiophlebia superstes (Odonata: Epiophlebiidae). Organisms Diversity \& Evolution DOI: 10.1007/s13127-012-0097-z.

Blanke, A., Greve, C., Wipfler, B., Beutel, R.G. \& Misof, B. (2012b) The identification of concerted convergence in insect heads corroborates Palaeoptera. Systematic Biology.

Blanke, A., Wipfler, B., Letsch, H., Koch, M., Beckmann, F., Beutel, R.G. \& Misof, B. (2012c) Revival of Palaeoptera - head characters support a monophyletic origin of Odonata and Ephemeroptera (Insecta). Cladistics, 28, 560-581.

Bybee, S.M., Ogden, T.H., Branham, M.A. \& Whiting, M.F. (2008) Molecules, morphology and fossils: a comprehensive approach to odonate phylogeny and the evolution of the odonate wing. Cladistics, 23, 1-38.

Carle, F.L. (1982) The wing vein homologies and phylogeny of the Odonata: a continuing debate. Societas Internationalis Odonatologica Rapid Communications, 4, 1-66.

Carle, F.L. (1995) Evolution, taxonomy, and biogeography of ancient gondwanian libelluloides, with comments on anisopteroid evolution and phylogenetic systematics (Anisoptera: Aeshnidae). Odonatologica, 24, 383-506.

Carle, F.L. (1996) Revision of Austropetaliidae (Anisoptera: Aeshnoidea). Odonatologica, 25, 231-259.

Carle, F.L., Kjer, K. \& May, M. (2008) Evolution of Odonata, with special reference to Coenagrionoidea (Zygoptera). Arthropod Systematics \& Phylogeny, 66, 37-44.

Carle, F.L. \& Louton, J.A. (1994) The larva of Neopetalia punctata and establishment of Austropetaliidae fam. nov. (Odonata). Proceedings of the Entomological Society of Washington, 96, 147-155.

Dumont, H.J., Vierstraete, A. \& Vanfleteren, J.R. (2010) A molecular phylogeny of the Odonata (Insecta). Systematic Entomology, 35, 6-18.

von Ellenrieder, N. (2002) A phylogenetic analysis of the extant Aeshnidae (Odonata: Anisoptera). Systematic Entomology, 27, 437-467.

Fiala, J.C. (2005) Reconstruct: a free editor for serial section microscopy. Journal of Microscopy, 218, 52-61.

Fleck, G. (2011) Phylogenetic affinities of Petaluridae and basal Anisoptera families (Insecta: Odonata). Stuttgarter Beiträge zur Naturkunde A, 4, 83-104.

Fleck, G., Brenk, M. \& Misof, B. (2008a) Larval and molecular characters help to solve phylogenetic puzzles in the highly diverse dragonfly family Libellulidae (Insecta: Odonata: Anisoptera): the Tetrathemistinae are a polyphyletic group. Organisms, Diversity \& Evolution, 8, 1-16.

Fleck, G., Ullrich, B., Brenk, M., Wallnisch, C., Orland, M., Bleidissel, S. \& Misof, B. (2008b) A phylogeny of anisopterous dragonflies (Insecta, Odonata) using mtRNA genes and mixed nucleotide/doublet models. Journal of Zoological Systematics and Evolutionary Research, 46, 310-322.

Fraser, F.C. (1957) A reclassification of the order Odonata. Royal Zoological Society of New South Wales, Sydney.

Garrison, R.W., Von Ellenrieder, N. \& Louton, J.A. (2006) Dragonfly genera of the New World: an illustrated and annotated key to the Anisoptera. JHU Press.

Holland, B.R., Spencer, H.G., Worthy, T.H. \& Kennedy, M. (2010) Identifying cliques of convergent characters: concerted evolution in the cormorants and shags. Systematic Biology, 59, $433-445$.
Klass, K.-D. (2008) The female abdomen of ovipositor-bearing Odonata (Insecta: Pterygota). Arthropod Systematics \& Phylogeny, 66, $45-142$

Lee, D.-C. \& Bryant, H.N. (1999) A reconsideration of the coding of inapplicable characters: assumptions and problems. Cladistics, $\mathbf{1 5}$, 373-378.

Letsch, H.O., Greve, C., Kück, P., Fleck, G., Stocsits, R.R. \& Misof, B. (2009) Simultaneous alignment and folding of $28 \mathrm{~S}$ rRNA sequences uncovers phylogenetic signal in structure variation. Molecular Phylogenetics and Evolution, 53, 758-771.

Li, J.-K., Nel, A., Zhang, X.-P., Fleck, G., Gao, M.-X., Lin, L.I.N. \& Zhou, J.I.A. (2012) A third species of the relict family Epiophlebiidae discovered in China (Odonata: Epiproctophora). Systematic Entomology, 37, 408-412.

Lohmann, H. (1996) Das phylogenetische system der Anisoptera (Odonata). Entomologische Zeitschrift, 106, 209-266.

Matushkina, N.A. (2008a) The ovipositor of the relic dragonfly Epiophlebia superstes: a morphological re-examination (Odonata: Epiophlebiidae). International Journal of Odonatology, 11, 71-80.

Matushkina, N.A. (2008b) Skeletomuscular development of genital segments in the dragonfly Anax imperator (Odonata, Aeshnidae) during metamorphosis and its implications for the evolutionary morphology of the insect ovipositor. Arthropod Structure \& Development, 37, 321-332.

Misof, B., Rickert, A.M., Buckley, T.R., Fleck, G. \& Sauer, K.P. (2001) Phylogenetic signal and its decay in mitochondrial SSU and LSU rRNA gene fragments of Anisoptera. Molecular Biology and Evolution, 18, 27-37.

Needham, J.G. \& Westfall, M.J. (1955) A manual of the Dragonflies of North America (Anisoptera) Including the Greater Antilles and the Provinces of the Mexican Border. University of California Press, Berkeley, CA.

Nixon, K.C. (2002) Winclada Version 1.00.08. Published by the author, Ithaca, NY.

Patterson, T.B. \& Givnish, T.J. (2002) Phylogeny, concerted convergence, and phylogenetic niche conservatism in the core liliales: insights from rbcL and ndhF sequence data. Evolution, 56, 233-252.

Pfau, H.K. (1991) Contributions to the functional morphology to the phylogenetic systematics of Odonata. Advances in Odonatology, $\mathbf{5}$, 109-141.

Rehn, A.C. (2003) Phylogenetic analysis of higher-level relationships of Odonata. Systematic Entomology, 28, 181-239.

Stampanoni, M., Marone, F., Modregger, P. etal. (2010) Tomographic Hard X-ray phase contrast micro- and nano-imaging at TOMCAT. 6th International Conference on Medical Applications of Synchrotron Radiation 1266.

Trueman, J.W.H. (1996) A prelimnary cladistic analysis of odonate wing venation. Odonatologica, 25, 59-72.

Wipfler, B., Machida, R., Müller, B. \& Beutel, R.G. (2011) On the head morphology of Grylloblattodea (Insecta) and the systematic position of the order, with a new nomenclature for the head muscles of Dicondylia. Systematic Entomology, 36, 241-266.

Wipfler, B., Wieland, F., DeCarlo, F. \& Hörnschemeyer, T. (2012) Cephalic morphology of Hymenopus coronatus (Insecta: Mantodea) and its phylogenetic implications. Arthropod Structure \& Development, 41, 87-100.

Wootton, R.J. (1992) Functional morphology of insect wings. Annual Review of Entomology, 37, 113-140.

Wootton, R.J. \& Kukalová-Peck, J. (2000) Flight adaptations in Palaeozoic Palaeoptera (Insecta). Biological Reviews, 75, 129-167.

Accepted 182012 


\section{QUERIES TO BE ANSWERED BY AUTHOR}

IMPORTANT NOTE: Please mark your corrections and answers to these queries directly onto the proof at the relevant place.

\section{Queries from the Copyeditor:}

AQ1. Deep level relationships: is it obvious what this means to any reader? Can you rephrase?

AQ2. assemblage of monophyletic: please clarify what you mean-the monophyletic assemblage or an assemblage of monophyletic missing word?

AQ3. functional dependence between the costal region: between this region and what?

AQ4. Pohl, 2010 has not been included in the Reference List, please supply full publication details.

AQ5. Betz et al., 2007 has not been included in the Reference List, please supply full publication details.

AQ6. Katoh et al., 2002 has not been included in the Reference List, please supply full publication details.

AQ7. Katoh et al., 2005 has not been included in the Reference List, please supply full publication details.

AQ8. Misof \& Misof, 2009 has not been included in the Reference List, please supply full publication details.

AQ9. Kück, 2010 has not been included in the Reference List, please supply full publication details.

AQ10. Goloboff et al., 2008 has not been included in the Reference List, please supply full publication details.

AQ11. Huelsenbeck \& Ronquist, 2001 has not been included in the Reference List, please supply full publication details.

AQ12. Ronquist \& Huelsenbeck, 2003 has not been included in the Reference List, please supply full publication details.

AQ13. Stamatakis et al., 2008 has not been included in the Reference List, please supply full publication details.

AQ14. L. depressa: in all figure captions please supply the full genus names

AQ15. Please provide the text for figure 7(a) and also please provide the artwork for figure 7(b).

AQ16. Corduliidae which are retrieved as paraphyletic groups: please confirm that is what you mean is that these three groups are both sister to Gomphidae and paraphyletic

AQ17. Please provide the citation for Figure 10.

AQ18. [?]: does this need to be included?

AQ19. Please provide the opening quote.

AQ20. E.: please give genus name in full

AQ21. Please provide the volume number and page range for Reference Black et al., 2012a.

AQ22. Please provide the volume number and page range for reference Blanke et al. (2012b).

AQ23. Please provide the city location of publisher for reference Garrison et al. (2006).

AQ24. Please provide the city location of conference for Reference Stampanoni et al., 2010.

AQ25. We have processed Figure(s) 3,4,5,6,7,9,11 in colour. If these figures are to be published in colour, please fill out CWA form if not yet done. 